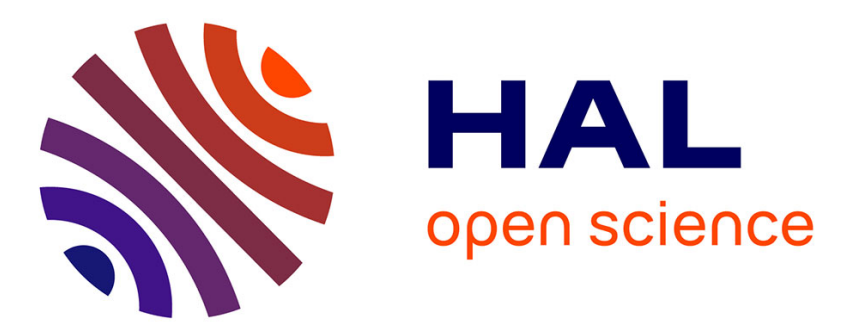

\title{
Geography and economic performance: Exploratory Spatial Data Analysis for Great Britain
}

Eleonora Patacchini, Patricia Rice

\section{To cite this version:}

Eleonora Patacchini, Patricia Rice. Geography and economic performance: Exploratory Spatial Data Analysis for Great Britain. Regional Studies, 2007, 41 (04), pp.489-508. 10.1080/00343400600928384 . hal-00514631

\section{HAL Id: hal-00514631 \\ https://hal.science/hal-00514631}

Submitted on 3 Sep 2010

HAL is a multi-disciplinary open access archive for the deposit and dissemination of scientific research documents, whether they are published or not. The documents may come from teaching and research institutions in France or abroad, or from public or private research centers.
L'archive ouverte pluridisciplinaire HAL, est destinée au dépôt et à la diffusion de documents scientifiques de niveau recherche, publiés ou non, émanant des établissements d'enseignement et de recherche français ou étrangers, des laboratoires publics ou privés. 


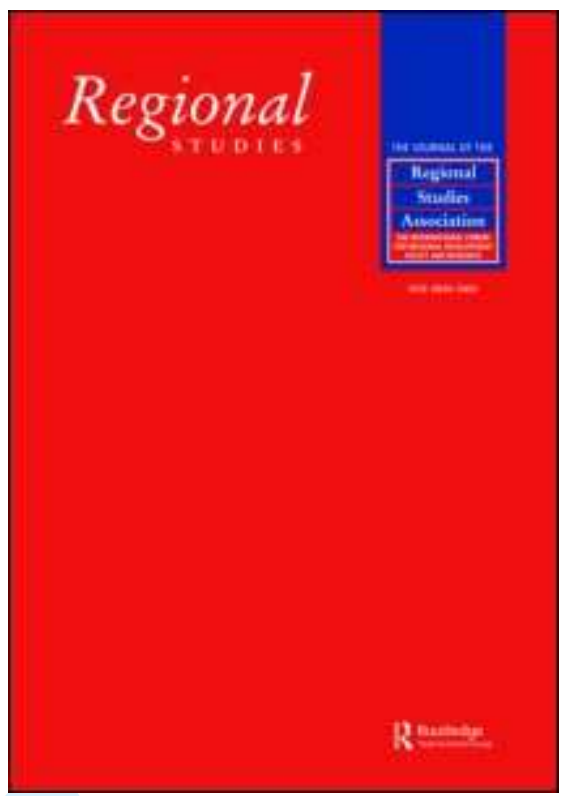

\section{Geography and economic performance: Exploratory Spatial Data Analysis for Great Britain}

\begin{tabular}{|r|l|}
\hline Journal: & Regional Studies \\
\hline Manuscript ID: & CRES-2005-0247.R1 \\
\hline Manuscript Type: & Main Section \\
\hline JEL codes: & $\begin{array}{l}\text { O4 - Economic Growth and Aggregate Productivity < O - Economic } \\
\text { Development, Technological Change, and Growth, R11 - Regional } \\
\text { Economic Activity: Growth, Development, and Changes < R1 - } \\
\text { General Regional Economics < R - Urban, Rural, and Regional } \\
\text { Economics, R12 - Size and Spatial Distributions of Regional } \\
\text { Economic Activity < R1 - General Regional Economics < R - Urban, } \\
\text { Rural, and Regional Economics, O18 - Regional, Urban, and Rural } \\
\text { Analyses < O1 - Economic Development < O - Economic } \\
\text { Development, Technological Change, and Growth }\end{array}$ \\
\hline \hline Keywords: & $\begin{array}{l}\text { regional disparities, income per worker, , productivity, , } \\
\text { occupational composition, , spatial autocorrelation }\end{array}$ \\
\hline \hline
\end{tabular}

\section{SCHOLARONE" Manuscripts}




\title{
Geography and Economic Performance:
}

\section{Exploratory Spatial Data Analysis for Great Britain}

\author{
Eleonora Patacchini* \\ University of Rome "La Sapienza" \\ Patricia Rice \\ University of Southampton
}

\begin{abstract}
This paper uses the techniques of exploratory spatial data analysis to analyse patterns of spatial association for different indicators of economic performance, and in so doing identify and describe the spatial structure of economic performance for Great Britain. This approach enables us to identify a number of significant local regimes - clusters of areas in which income per worker differs significantly from the global average - and investigate whether these come about primarily through spatial association in occupational composition or in productivity. Our results show that the contributions of occupational composition and productivity vary significantly across local regimes. The 'winner's circle' of areas in the south and east of England benefits from both above average levels of productivity and better than average occupational composition, while the low income regime in the north of England suffers particularly from poor occupational composition.
\end{abstract}

Key words: regional disparities, income per worker, productivity, occupational composition, spatial autocorrelation

JEL Classification: O18, O4, R11, R12

We would like to thank Henry Overman and Anthony Venables for valuable comments. The research is funded by the Evidence Based Policy Fund, HM Treasury, Department of Trade and Industry and the Office of the Deputy Prime Minister of the UK as part of the project "Regional inequalities in the UK: productivity, earnings and skills". *Corresponding author: Eleonora Patacchini, University of Rome "La Sapienza", Faculty of Statistics, P.le A. Moro, 5, 00185, Rome, Italy. Email: eleonora.patacchini@uniroma1.it 


\section{Introduction}

Recent research in economic geography has drawn attention to the potential for positive externalities arising from agglomeration of economic activity (Fujita, Krugman and Venables, 1999, Ottaviano and Puga, 1997). The benefits to firms and workers being located close to each other in space may come from a variety of sources: knowledge spillovers, thick market effects in the labour market, proximity to consumers and to specialist input suppliers in markets with trade costs and increasing returns. ${ }^{1}$ As a result of these developments, economists have started to pay closer attention to the spatial configuration of economic data for evidence of significant spatial clustering.

The visualisation and exploration of spatial data can provide valuable insights into the nature and extent of spatial clustering in economic variables (Dall'Erba, 2005; Lopez-Bazo et al. 1999). However, much of the empirical work undertaken to date has tended to focus on identifying the spatial properties of a single economic variable - usually GDP per capita or its growth rate (see for example, Rey and Montouri, 1999; Ertur and Le Gallo, 2003; Roberts, 2004). In this paper, we use the techniques of exploratory spatial data analysis to compare and contrast patterns of spatial association in related measures of economic performance. More specifically, we decompose subregional income per worker into a productivity component and an occupational composition component, and analyse the spatial structure of each of these variables. This approach offers valuable insights into the sources of spatial dependence and spatial heterogeneity in income per worker. This is very distinct from the information that may be gained using spatial regression methods which focus on identifying and estimating average effects across space. ${ }^{2}$

The focus of our analysis is the significant disparities in economic performance that persist across the sub-regions of the UK. These are well documented, most recently in the Treasury report "Productivity in the UK: the Local Dimension" (July 2003). However, views differ as to whether these disparities represent a significant divide between an impoverished 'north' and an affluent 'south'; or whether the picture is more diffuse with intra-regional differences in economic outcomes as significant as those between the major regions of the UK. (Adams and Robinson, 2002, HM 
Treasury, 2003). Data for 2001 shows that income per capita in London is 154 percent of the national average, as compared with just 73 percent of the national average in the North East region and 86 percent in Yorkshire and Humberside. That said, the cities of Leeds and York are both within the upper quartile of the UK distribution of income per head, while areas of Outer London fall in the lower quartile.

We start by examining income per worker in the NUTS3 sub-regions of Great Britain and address the following questions ${ }^{3}$. What is the relationship between the economic performance of one area and that of its neighbours and over what range does this relationship persist? Is there evidence of spatial clustering with areas of high (low) income surrounded by 'neighbours' with similar levels of income? Or are high performing areas observed as atypical areas of high productivity surrounded by lower performing neighbours? These questions are addressed using exploratory spatial data analysis techniques to characterise the relationship between the value of an economic variable in one region and that of its neighbours, and thereby detect patterns of spatial association, spatial clusters, and atypical localisations.

The analysis finds strong evidence of a positive spatial association in income per worker at the sub-regional (NUTS3) level in Great Britain. In other words, areas of relatively high (low) income tend to be located 'close to' other areas of high (low) income. The results show that for these purposes 'close' is within an estimated travel time of some 90 minutes. At distances beyond this, the evidence of positive spatial association persists but is weakening. Within this global structure, one can identify significant local regimes - clusters of areas in which the value of income per worker differs significantly from the average for the UK as a whole. Thus, there is strong evidence of a 'winner's circle' in the south and east of England - a cluster of areas with income per worker significantly higher than the global average. There is evidence also - albeit less strong - of two further regimes, both of a low-income type. The larger of these is located in the north west centred around the metropolitan areas of Liverpool and Manchester; while the second smaller cluster is in the south-west of England. Within each regime, there are atypical areas with dissimilar
Deleted: spatial outliers Deleted: -

Deleted: or spatial outliers (Haining, 1990; Anselin, 1988). 
values to their neighbours. For example, within the high-income regime in the south and east, metropolitan areas such as Brighton and Hove and Portsmouth are significantly underperforming relative to surrounding areas.

Having identified the spatial structure of income per worker, we examine whether this derives primarily from spatial dependence in the types of jobs available or in productivity in a given job. A location may derive high income per worker from having a high concentration of good quality (i.e. well paid) jobs. Or, it may that for some reason - possibly related to the agglomeration effects identified in the economic geography literature - output per worker within a given occupation is higher here than elsewhere. As far as the high-income regime in the south and east of Great Britain is concerned, the cluster benefits from both above average job quality and higher than average worker productivity in given jobs. The picture within the low-income regimes is more mixed. For the north west, the evidence suggests that occupational composition plays the bigger role in shaping the spatial structure of income, while in the south west, low worker productivity rather than poor quality jobs appears to be the issue.

The paper is structured as follows. In Section 2, we describe the data used in this study and examine the basic descriptive statistics relating to the levels and dispersion of the variables across the NUTS3 areas of Great Britain. Section 3 presents the evidence relating to the spatial distribution of income per worker across the sub-regions of Great Britain. Section 4 compares these results with those for the data relating to the occupational composition and productivity. Section 5 concludes.

\section{Income, Earnings and Productivity: Data and Descriptive Statistics}

Our analysis is based on data for the sub-regional NUTS3 spatial units of Great Britain. There are 126 NUTS3 administrative areas in Great Britain but, in order to compile a consistent dataset, a number of these are combined to give a sample of 119 sub-regional units (that we will term 'areas'). The data series relate to the period 1998 to 2001 and the four years of data are averaged in order to remove some of the short-run volatility. Full details of the sample and the data used are provided in the Data Appendix to this paper (Appendix 1). 
Several different types of income data are available. ${ }^{4}$ Estimates of workplace-based gross value-added at the NUTS3 level are calculated according to the income approach by the Office of National Statistics (ONS, 2003). We construct a measure of GVA per hour worked by employees, taking as the denominator an estimate of the total hours worked by employees in the area. A limitation of GVA as a measure of income is that it is sensitive to the assumptions made in allocating profits and other non-wage income across the NUTS 3 areas (see ONS 2003 for further discussion). An alternative measure that avoids this problem focuses on income from employment only and for this we use data for average hourly earnings from the New Earnings Surveys for the relevant years. In so far as the measurement errors in the income variables are temporary, they are mitigated by averaging the data over the four year period.

\section{(insert Table 1 here)}

Table 1 gives summary statistics for each of these measures and the relationship between them. The numbers in brackets are the same statistics with Inner London (East and West) excluded from the sample. Correlation coefficients between each of the variables are reported in the lower part of the table. GVA per hour worked $\left(g_{i}\right)$ varies across the 119 NUTS3 regions from 14.79 in Stoke on Trent to 25.20 in Inner London (West) with a mean of 18.67 and a coefficient of variation of 0.10 . Average hourly earnings $\left(e_{i}\right)$ displays an even greater degree of spatial variation although this falls significantly with the exclusion of Inner London from the sample. As one would expect, the two income series are highly correlated with a correlation coefficient of 0.76 . However, there are some major outliers, most notably the two Inner London areas where average earnings are high relative to GVA per hour worked. In general, the areas with a high ratio of average earnings to GVA per hour worked tend to be the metropolitan areas including East Merseyside, Solihull, Brighton and Hove and Liverpool, as well as Inner London. By contrast, average hourly earnings tend to be low relative to GVA per hour worked in more rural areas - Torbay, West Lothian, East Ayrshire, South West Wales.

Spatial variation in average earnings derives from two sources - differences in the wage rates paid to workers in a given occupation, and differences in the occupational composition of 
employment. These two contributions to the spatial structure of average earnings can be separated out as follows. Let $w_{i}^{k}$ and $l_{i}^{k}$ denote the wage and level of employment in occupation $k$ and area $i$. Total employment in area $i$ is $L_{i}=\Sigma_{k} l_{i}^{k}$, and the share of occupation $k$ in employment in this area is $\lambda_{i}^{k}=l_{i}^{k} / L_{i}$. The average wage of occupation $k$ in the economy as a whole (i.e. aggregating across all $i$ ) is given by $\bar{w}^{k}=\Sigma_{i} l_{i}^{k} w_{i}^{k} / \Sigma_{i} l_{i}^{k}$, while $\bar{\lambda}^{k}=\Sigma_{i} l_{i}^{k} / \Sigma_{i} L_{i}$ is the share of occupation $k$ in total employment for the economy as a whole. It follows that average earnings in area $i$, $e_{i}$, may be decomposed as follows:

$$
e_{i} \equiv \Sigma_{k} w_{i}^{k} \lambda_{i}^{k}=\Sigma_{k} w_{i}^{k} \bar{\lambda}^{k}+\Sigma_{k} \bar{w}^{k} \lambda_{i}^{k}+\Sigma_{k}\left(w_{i}^{k}-\bar{w}^{k}\right)\left(\lambda_{i}^{k}-\bar{\lambda}^{k}\right)-\Sigma_{k} \bar{w}^{k} \bar{\lambda}^{k}
$$

The first term on the right-hand side of (1) is the average level of earnings at location $i$ conditional on the occupational composition being the same as for the economy as a whole; it will be denoted $q_{i}=\Sigma_{k} w_{i}^{k} \bar{\lambda}^{k} \cdot q_{i}$ measures the spatial variation in wages while controlling for occupational structure, and as such reflects spatial differences in productivity. ${ }^{5}$ We will refer to it as the productivity index. The second term on the right-hand side measures the average level of earnings of area $i$ given its specific occupational composition but assuming that the wage rate for each occupation is equal to the UK average in that occupation. It will be denoted $c_{i}=\Sigma_{k} \bar{w}^{k} \lambda_{i}^{k}$ and referred to as the occupational composition index. The remaining terms in (1) measure the covariance in earnings and composition across occupations in area $i$ and will be denoted by $r_{i}$. Before proceeding it is important to note that (1) is an arithmetic decomposition of the data and does not depend on any particular model of the determinants of productivity or of occupational composition, or of the relationship between them. The value of the decomposition lies in allowing us to identify ex post the contribution of the spatial variation in productivity and in occupational composition to the overall spatial structure of income per worker. In practise the quality of the decomposition depends on the level of occupational disaggregation that is feasible given available data. Ideally, the level of occupational disaggregation should be such that the occupational categories are relatively homogenous, but in practise sample sizes restrict the level of disaggregation that is practical 

employment shares by occupation taken from the Labour Force Survey are used to compute the productivity index and the occupational composition index for each of the NUTS3 areas of Great

Britain $_{\checkmark}$ The productivity index, $q_{i}$, is constructed from data on earnings by occupation for each of 38 minor occupational groups, using as weights the share of each occupation in the total employment of Great Britain as a whole. The composition index, $c_{i}$, requires data on employment shares by occupation at the level of the NUTS3 area, which is available from the Labour Force Survey but in this case, reliable estimates are available only for the 9 major occupational groups.

Summary statistics for these indices are reported in Table 1, columns 3 to 5. First, note that the sample properties of the productivity index do not vary significantly with the level of occupational disaggregation. As we would expect, the more disaggregated index (i.e. the one computed for 38 distinct occupational categories) displays a little less spatial variation. However, the two indices are very highly correlated $(0.987)$ and their relationship with the other variables appears very similar. As one might expect, the occupational composition index and the productivity index are positively correlated so that areas with high productivity tend to have a good occupational composition also, although the correlation at approx. 0.66 is far from perfect. Variance in the productivity index accounts for some $60 \%$ of the overall variance in average hourly earnings. ${ }^{6}$ The remaining 40 percent is attributable to variance in the composition index and the covariance term.
Deleted: Ideally, the level of occupational disaggregation should be such that the occupational categories are relatively homogenous, but in practise sample sizes restrict the level of disaggregation that is practical 


\section{Spatial Structure of Income}

In this section of the paper, we examine the spatial structure of income per worker across the UK. Is it appropriate to characterise the outcome as a 'north-south' divide between the affluence of the south of England and the impoverishment of the regions of the north (IPPR 2003)? At first sight, the maps of the NUTS3 regions of Great Britain designated according to the quintiles of the income distribution in Figure 1 would appear to support this view. In terms of GVA per hour worked, the south and east of England has a preponderance of NUTS3 regions in the top 40 percent of the distribution, while the regions in the lowest quintile tend to be located in the north of the country. The picture for average hourly earnings is, however, less clear cut, with areas of relatively high (low) average earnings appearing more spatially dispersed. Do the groupings of high and low values apparent in Figure 1 represent a statistically significant departure from spatial randomness? To answer that question, we use the methods of exploratory spatial data analysis to describe and formally test the global and local spatial properties of the two income measures - GVA per hour worked and average hourly earnings. (For details on these methods see Haining, 1990, Anselin, 1995a and 1995b, Getis and Ord, 1992, Ord and Getis, 1995.)

A basic characteristic that distinguishes spatial data from other types of cross-section data is the spatial arrangement of the $n$ observations. For purposes of exploratory data analysis, the spatial linkages or proximity of the units of observations are summarised by defining a $n \times n$ spatial weight matrix, $W=\left\{W_{i j}\right\}$ where $W_{i j}=1$ if sites $i$ and $j$ are designated as neighbours, and $W_{i j}=0$ otherwise. A number of alternative criteria can be used for the specification of the neighbourhood set. A standard approach is to define proximity in terms of contiguity i.e. areas are designated as neighbours if they share a common boundary. However, where the basic units are defined by administrative boundaries, as in this case, this approach can give rise to neighbourhoods that vary greatly in terms of both the number of linkages and the geographical area covered. A more economically meaningful measure of proximity may be obtained by considering travel times between the units so that areas are neighbours if they are within a specified travel time $d$ of each other. In the analysis 
that follows, spatial proximity is measured in terms of the average road journey time between the population centres of NUTS3 areas. ${ }^{7}$ The estimated road journey time between a pair of NUTS3 areas in the sample varies between 21 minutes and 748 minutes, with a mean journey time of 237.5 minutes and a median journey time of approximately 220 minutes. The potential interactions between locations are summarised by the matrix $W_{d}=\left\{W_{i j, d}\right\}$ where $W_{i j, d}=1$ if the spatial units $i$ and $j$ are within $d$ minutes of each other and $W_{i j, d}=0$ otherwise, where initially values of $d=\{30$, $60,90,120,150,180\}$ are considered.

\subsection{Global Spatial Properties}

Under the assumption of spatial randomness, any grouping of high or low values of the variable in space is totally spurious. The existence of a spatial structure is detected by the presence of spatial correlation that can be defined as the "coincidence of value similarity with locational similarity" (Anselin, 2001). There is positive spatial autocorrelation when high or low values of a random variable tend to cluster in space and there is negative spatial autocorrelation when geographical areas tend to be surrounded by neighbours with very dissimilar values, To investigate the global properties of the data, we consider two measure of global spatial autocorrelation, the Moran's I and the Geary's c statistics. (Cliff and Ord, 1981).

(insert Table 2 here)

Table 2 reports the Moran's I statistic and the Geary's $c$ statistic for the two alternative income measures - GVA per hour worked and average hourly earnings - based on (row standardised) spatial proximity matrices corresponding to estimated road journey times of up to 30 , $60,90,120,150$ and 180 minutes. Along with the test statistics, we report the standardized $z$-value for each statistic, the associated significance level, $p l$, assuming the (asymptotic) distributions of $I$ and $c$ are approximately normal, and an alternative indicator of statistical significance, $p 2$, based on the conditional randomisation approach with 10000 permutations.

These results provide strong evidence of positive spatial autocorrelation in income across the NUTS3 regions of Great Britain. NUTS3 regions with relatively high (low) income are located 
close to other sub-regions with relatively high (low) income more often than would be observed if their locations were purely random. Both the Moran's $I$ and Geary's $c$ statistics are highly significant irrespective of the chosen inference strategy (i.e. both $p 1$ and $p 2$ are always close to 0 ) at distances of up to 120 minutes travel time. The values of the standardised test statistics, $\mathrm{z}(I)$ and $z(c)$, suggest that the spatial linkages are strongest at distances of up to 90 minutes travel time. ${ }^{8}$ Moreover, these findings hold irrespective of whether we measure income in the region by GVA per hour worked or by average hourly earnings.

The Moran scatterplot shows the relationship between the value of the variable of interest for a given area $i$ and the average value for the areas in its neighbourhood set. The Moran's $I$ measure of global spatial autocorrelation is formally equivalent to the OLS estimate of the slope coefficient of the line fitted to the Moran scatterplot and hence standard regression diagnostics may be used to detect outliers and to identify individual areas that exert strong influence on the global Moran's I statistic (Anselin, 1996). Figure 2 depicts the Moran scatterplots for the two income variables based on the spatial weight matrix for $d=90$ minutes. Simple visual inspection of Figure 2 identifies no potential outliers as far as the GVA data is concerned, but Inner London (West) does appear to have a very large residual in respect of average hourly earnings. Formal statistical tests confirm that Inner London (West) is a significant outlier in this case. ${ }^{9}$ However, dropping Inner London (West) observation from the average hourly earnings series has no significant impact on the measures of global spatial autocorrelation reported in Table 2, and there is nothing to suggest that the finding of strong positive spatial correlation in average earnings is being driven by this outlier (see Table A1 in Appendix 2).

The four quadrants of the so-called Moran scatterplot correspond to the four types of local spatial association between a location and its neighbours: HH (upper right), contains areas with a high value surrounded by areas with high values, HL (lower right) consists of high value areas with relatively low value neighbours; LL (lower left) consists of low value areas surrounded by other areas with low values; LH (upper left) contains low value areas with high value neighbours. In the 
case of GVA per hour worked, $65 \%$ of the NUTS3 regions of Great Britain display association of similar values; $28 \%$ of the $\mathrm{HH}$ type and $37 \%$ of the LL type. For average hourly earnings, the proportion is even higher with $80 \%$ of NUTS3 regions characterised by positive spatial association, of which $36 \%$ are of the HH type and $44 \%$ of the LL type. The Moran scatterplot may be used also to identify atypical areas, i.e. areas deviating from the global pattern of positive spatial autocorrelation. These correspond to sample points in the HL (lower right) quadrant or the LH (upper left) quadrant of the scatterplot. For example, the NUTS3 regions of Cheshire, Derby and Edinburgh appear to be areas of relatively high income with low income neighbours on the basis of both GVA per hour worked and average hourly earnings. By contrast, Leicester, Dudley and Sandwell, Southend-on Sea appear to be areas of relatively low income surrounded by high income neighbours. The significance of these apparent local patterns of spatial association are explored in greater detail in the next section of the paper

\subsection{Local Spatial Regimes}

Different statistics of local spatial correlation have been developed to assess spatial dependence in a particular sub-region of the sample. These statistics describe the association between the value of the variable at a given site and that of its neighbours, and between the value within the neighbourhood set and that for the sample as a whole. The most widely used are the Getis-Ord's G statistic and the local Moran's I. The Getis-Ord's G statistic (Getis and Ord, 1992), is based on a comparison of the average value within a given neighbourhood set and the global average, and as such may be used to identify local regimes of relatively high or relatively low values of a variable. The local Moran's I statistic (Anselin, 1995a) measures the correlation between the value for a given area and that for its neighbours, and may be used to identify atypical localisations as well as clusters of high or low values.

A number of complications arise in assessing the significance of local indicators of spatial association. First, the distribution of both the local Moran's I and the Getis-Ord's G statistics are affected by the presence of global spatial association, and hence inference based on the normal 
approximation is likely to be misleading (Anselin, 1995a) Given the evidence of global spatial autocorrelation in Table 2, the nonparametric approach of conditional randomisation provides a more reliable basis for inference in this case. The conditional randomisation method yields the same empirical reference distribution for both the local Moran's $I$ and the Getis-Ord's G statistics and so inference based on this nonparametric approach gives identical results for the two statistics (Anselin $1995 \mathrm{a})$.

A second complicating factor is that the local statistics for any pair of locations, $i$ and $j$, are correlated whenever their neighbourhood sets contain common elements (Ord and Getis, 1995). Given this, Ord and Getis suggest using a Bonferroni bounds procedure to assess significance such that for an overall significance level of $\alpha$, the individual significance level for each observation is taken as $\alpha / n$ where $n$ is the number of observations in the sample. In this particular study with a sample of 119 observations, an overall significance level of 0.05 implies an individual significance level for each observation of just 0.00043 . However, in practise for any given location, the number of other locations in the sample with correlated local statistics is likely to be considerably small than $n$, and so this procedure is expected to be overly conservative $\frac{10}{v}$

For present purposes, we compute both the Getis-Ord's G and the local Moran's I statistic for each NUTS3 area using the spatial weights matrix for $d=90$ minutes, the distance at which spatial linkages seem to be strongest (see Table 2). ${ }^{11}$ The values of the local statistics together with the associated significance levels based on the normal approximation and that derived using the conditional randomisation method are reported in full in Table $\mathrm{A} 2$ of Appendix 2.12 Inference based on the normal approximation and that based on the conditional permutation approach give very similar results in the case of the Getis-Ord's G statistic, but not for the local Moran's I statistic. This is not surprising, given that it is now common knowledge that the reference distribution of the local Moran's I statistic deviates substantially from the normal distribution (see, e.g., Tiefelsdorf, 2002). Figure 3 shows the NUTS3 regions for which the local statistics are significant at the 0.05 level based on the conditional permutation approach. By considering the two extreme significance levels 
of 0.005 and 0.00043 - the first applying if the individual local statistics are independent, while the second is appropriate if all the local statistics are correlated - we are able to place bounds on the extent of local spatial regimes in the data.

In the case of the GVA per hour worked data, two spatial regimes are clearly identified. The largest is a 'high-income' regime - a cluster of NUTS3 areas in which GVA per hour worked is significantly higher than the average for the sample as a whole - located in the south and east of England. This regime includes the majority of NUTS3 regions within the East, London and South East regions, extending to Warwickshire, Northamptonshire and Cambridgeshire to the north, Oxfordshire and Wiltshire to the west, Essex and Kent to the east. Adopting the more conservative criteria implied by using the Bonferroni procedure leaves this regime largely unchanged - only Warwickshire to the north and Wiltshire to the west are excluded. Within this high-income regime, the local Moran's I statistic identifies a number of atypical areas i.e. areas that exhibit negative spatial correlation with their neighbours. Brighton and Hove and Portsmouth in the south, Medway and Southend-on-Sea in the east, Peterborough and Suffolk to the north are identified as atypical low income areas on the periphery of the high income regime.

The second significant regime is a 'low income' type - a cluster of areas in which average GVA per hour worked is low relative to the global average. This regime covers the North West and North East regions of the UK extending south to South Yorkshire and Stoke-on-Trent and west into Wales. In this case, adopting the tighter criteria for statistical significance shrinks the regime considerably such that it is centred on the metropolitan areas of Manchester, Merseyside and west Yorkshire in the north-west of England. Here too the local Moran's $I$ statistic identifies a number of atypical areas within the low income cluster. Cheshire, York and North Yorkshire are all areas with significantly higher GVA per hour worked than the average for their neighbours.

How does this picture change if we focus on employment income only? As far as the "high income' regime in the south of the UK is concerned, the answer is very little. The main difference is that some areas that appeared to be underperforming relative to their neighbour in terms of GVA are
Deleted: local Moran

Deleted: local Moran 
not similarly placed with respect to earnings, and vice versa. For example, the cities of Brighton and Hove and Portsmouth are significantly worse off than their neighbouring areas in terms of GVA per hour worked but not average hourly earnings. However, the evidence for a 'low income' regime in the north of Great Britain in terms of the earnings data is less strong. Applying the more conservative criteria, there are no neighbourhoods for which the average for hourly earnings is significantly below the global average. Relaxing the criteria and applying a significance level of 0.05 for each observation, a 'low income' regime emerges which includes Northumberland and Durham in the north east, Cumbria in the north west and areas around Manchester and the west of Yorkshire but this is far less extensive than is apparent in the GVA data. Furthermore, at this significance level, we identify a second low earnings cluster centred around Plymouth and Devon in the south west of England.

The question arises as to the sensitivity of these findings to the particular choice of spatial weight matrix. Is it the case that changing the cut-off point in terms of travel times results in significant changes in the statistical significance of the local indicators of spatial association? Following the approach used in Ertur and Le Gallo (2003), our results suggest not. We find that all areas with local statistics significant at the 0.05 percent level with a cut-off point of 90 minutes in terms of travel time are still associated with a significant value using a cut-off of 120 minutes, and the same is true when we compare 120 minutes with 150 minutes, As the maximum travel time is extended and more neighbours are included in the structure of proximity, so the proportion of the areas with a significant value for the local statistic tends to increase. Moreover, considering the transitions of the areas between spatial regimes, we find that the tables are largely diagonal implying that an area tends to remain in the same spatial regime irrespective of the choice of the spatial weight matrix. $\frac{13}{}$ On the basis of these findings we conclude that the identification of spatial regimes, local clusters and atypical areas documented in Table A2 is robust to the spatial scale of the weight matrix.
Deleted: spatial outliers

Deleted: escribed in Figures 3 and 4 
To sum up, across Great Britain as a whole, regions of high/low income tend to be located close in terms of travel time to other regions of high/low income. This result holds whether we measure income broadly in terms of GVA per hour worked or, more narrowly, in terms of average hourly earnings. Does the evidence endorse the stereotypical view of a north-south divide in prosperity? To some extent, although is more appropriate to characterise the divide as one between a 'winner's circle' in the south east corner of England and the remainder of the country. The NUTS3 regions in the south and east of Great Britain are strongly identified as a high income regime - a cluster of areas for which average income within the cluster is significantly above the average for Great Britain as a whole. The evidence that areas in the north of England constitute a distinct 'low income' regime is more tentative. The data for GVA per hour worked does point to a cluster of areas centred around the metropolitan areas of Manchester, Merseyside and west Yorkshire with average income significantly lower than the global average for Great Britain as a whole. However, if we consider income from employment only, the evidence for a 'low income' regime is much weaker.

\section{Spatial Structure of Earnings: Productivity v. Occupational Composition}

Having identified the spatial structure of average hourly earnings in Great Britain, we turn now to the question of whether this derives primarily from spatial variation in types of jobs available or from in worker productivity in given jobs. More specifically, is the high income regime in the south and east of Great Britain due to the fact that productivity, and hence wages, in a given occupation is higher in these areas, or is it because these areas have better jobs than elsewhere? For this purpose, we analyse the global and local spatial properties of the productivity and occupational composition indices described in Section 2.

\section{(insert Table 3 here)}

The global test statistics reported in Table 3 point to positive spatial autocorrelation in both the productivity index and the occupational composition. The results for the productivity index are very close to those obtained for average hourly earnings, with both the Moran's I and the Geary's $c$ 
measures statistically significant at distances up to 120 minutes travel time. Areas with relatively high (low) productivity tend to be located close to other areas with relatively high (low) productivity. By comparison, the degree of positive spatial association displayed by the occupational composition index is less strong, and the Geary's $c$ statistics fails to reject the null hypothesis of no spatial association at travel times within 30 minutes and beyond 120 minutes. For both occupational composition and the productivity index, the spatial linkages appear strongest over distances of up to 90 minutes travel time as before. ${ }^{14}$ Thus at the global level, positive spatial association in worker productivity appears to play a major role in driving positive spatial association in income per worker.

Table A3 (in Appendix 2) reports the results of the local indicators of spatial association Getis Ord and local Moran's I statistics - in respect of productivity and occupational composition. Figure 4 shows the NUTS3 regions for which the local indicators of spatial association - Getis Ord and local Moran's I statistics - in respect of productivity and occupational composition are statistically significant at the 5 percent level ${ }^{15}$ What do these tell us about the factors giving rise to the local spatial regimes in income per worker described in Section 3? The first point to note is that the high-income regime identified in the earnings data is reproduced here in both the productivity index and the occupational composition index. The cluster of high income areas in the south and east of Great Britain derives its relative prosperity from both higher than average productivity (and hence a higher than average level of wages in any given occupation), and better than average occupational composition (i.e. a higher than average proportion of better paid jobs).

The local Moran's I provides further insights into the presence of atypical areas within this cluster - those NUTS3 regions which are underperforming relative to their neighbours in terms of average hourly earnings. Of the four significant atypical areas in the high earnings cluster, three regions - Southend-on-Sea, East Sussex and Wiltshire - are found to be atypical areas in respect of the productivity index but not the occupational composition. In other words, in these areas, the low level of earnings relative to their neighbours is primarily the result of low wages for a given set of 
occupations, rather than due to a poor occupational composition. Only for the Medway region would it appear that occupational composition is mainly responsible for the poor performance in terms of average hourly earnings.

What of the low earnings regime identified in the north-west of Great Britain? This regime is largely reproduced in the data for occupational composition. The NUTS3 areas which make-up the low earnings regime are in the majority of cases, areas with a poor occupational structure relative to the global average. Some of these areas - Northumberland and Tyneside, Bradford and Calderdale - are underperforming relative to the global average with respect to the productivity

index also. Likewise, the atypical areas within this low income regime are identified as atypical areas with respect to occupational composition. These results suggest that the spatial structure of occupational composition is playing the more influential role in shaping the low earnings regime in the north of England. The situation appears rather different in the south west of England where there is weak evidence of a low earnings regime also. Here the cluster is associated with low productivity and hence low wages relative to the global average, rather than with poor occupational composition.

\section{Concluding Remarks}

This paper uses the techniques of exploratory spatial data analysis to investigate the contribution of differences in types of jobs and differences in productivity for a given job to the spatial variation in income per worker across Great Britain. This approach not only identifies global patterns of spatial association but also highlights the roles played by occupational composition and productivity in observed spatial heterogeneity. In this respect, the methods are complementary to the techniques of spatial regression analysis which focus on the identification and estimation of average effects across a given space.

The formal statistical analysis confirms that the spatial distribution of income per worker across the sub-regions of Great Britain is not random. Whether we consider average hourly earnings or the more broadly defined GVA per hour worked, there is strong evidence of positive spatial 
association in income per worker - areas of relatively high (low) income tend to be located 'close to' other areas of high (low) income, where for these purposes 'close' is within an estimated road journey time of some 90 minutes. Moreover, while both occupational composition and worker productivity display positive spatial autocorrelation, the degree of spatial association is far stronger for productivity. Controlling for occupational composition, areas with high (low) wages tend to be located close to other areas of high (low) wages; a picture consistent with the hypothesis of significant returns to agglomeration.

Within this overall global pattern, we are able to identify significant local regimes - spatial clusters of areas in which the measures of economic performance diverge significantly from the average for the economy as a whole. The most clear cut of these is the high income regime in the south and east of England - a large cluster of areas for which both GVA per hour worked and average hourly earnings are significantly higher than the global average. Elsewhere in Great Britain, we find weak evidence of low income regimes - one in the north of England, and a second smaller regime in the south west of the country. One interesting observation to emerge from this investigation is that the evidence of underperformance in areas in the north of England is much stronger in the data for GVA per hour worked than in that for average hourly earnings. This evidence suggests that the these areas are at a particular disadvantage with respect to the distribution of non employment income - profits, trading surpluses, rents etc. However, questions remain over the reliability of the methods used to allocation these types of income across NUTS 3 areas when compiling the GVA estimates, and further investigation is needed.

While this analysis is largely descriptive, it does provide some insights into the economic factors underlying these local spatial patterns, and hence inform policy. The high earnings regime in the south and east of Great Britain is reproduced in the data for both productivity and occupational composition. The locations in this 'winners circle' benefit from both above average level of productivity and a better than average occupational composition. As far as the low earnings areas of the north west of Great Britain is concerned, occupational composition rather than productivity 
emerges as the more significant factor. - poorer quality jobs than the average for the country as a whole. By contrast, in the south west of England, below average earnings is the result of poor productivity rather than worse than average occupational composition. These findings highlight the spatial heterogeneity of economic performance across the UK, and the need for detailed analysis of local outcomes in order to identify the appropriate policy tools.

\section{References}

ADAMS, J. and P. ROBINSON (2002) A New Regional Policy for the United Kingdom, London, Institute for Public Policy Research.

ANSELIN, L. (1988) Spatial Econometrics; Methods and Models, Dordrecht, Kluwer.

ANSELIN, L. (1995a) Local indicators of spatial association-LISA, Geographical Analysis 27, 93115.

ANSELIN, L. (1995b) Spacestat Version 1.80 User's Guide, Regional Research Institute, West Virginia University, Morgantown WV.

ANSELIN, L. (1996) The Moran scatterplot as an ESDA tool to assess local instability in spatial Association, in Fisher M, Scholten HJ, Unwin D (eds), Spatial Analytical Perspectives on GIS, London: Taylor and Francis.

ANSELIN, L. (2001) Spatial econometrics, in Baltagi B (eds) Companion to Econometrics, Oxford: Basil Blackwell.

CLIFF, A. and J.K. ORD (1981) Spatial Processes, Models and Applications, London, Pion.

DALL'ERBA, S. (2005) Distribution of regional income and regional funds in Europe 1989-1999:

An exploratory data analysis, The Annals of Regional Science 39, 121-148.

Deleted: pp.

ERTUR, C. and J. LE GALLO, (2003) Exploratory spatial data analysis of the distribution of regional per capital GDP in Europe 1980-1995, Papers in Regional Science 82, 175-201.

Deleted: pp.

FINGLETON, B. (2001) Equilibrium and economic growth: spatial econometric models and simulations, Journal of Regional Science 41, 117-147. 
FINGLETON, B. (2003) Increasing returns: evidence from local wage rates in Great Britain,

Oxford Economic Papers 55, 716-739.

FUJITA, M., P. KRUGMAN and A.J.VENABLES (1999) The Spatial Economy: Cities, Regions and International Trade, Cambridge (MA), MIT Press.

FUJITA, M. and J.THISSE (2002) The Economics of Agglomeration, Cambridge, Cambridge University Press.

GETIS, A. and J.K. ORD (1992), The analysis of spatial association by use of distance statistics, Geographical Analysis 24, 189-206.

ORD, J.K. and A. GETIS _(1995) Local spatial autocorrelation statistics; distributional issues and an Deleted: , A. and J.K. Ord application, Geographical Analysis 27, 286-305.

HM Treasury (2003) Productivity in the UK - The Local Dimension, London: HMT( July).

HAINING, R. (1990) Spatial Data Analysis in the Social and Environmental Sciences, Cambridge: Cambridge University Press.

LOPEZ-BAZO E, VAYÀ E, MORA A.J and J SURIÑACH (1999) Regional economic dynamics and convergence in the European Union, Annals of Regional Science 33, 343-370.

Office of National Statistics (2003) NUTS 3 Gross Value Added: Methods and Background, London: ONS (December).

OTTAVIANO, G. and D. PUGA (1997) Agglomeration in the Global Economy: A Survey of the 'New Economic Geography, Centre for Economic Policy Discussion Paper 1699, London:CEPR.

REY, S.J. and B.D. MONTOURI (1999) US regional income convergence: a spatial econometric perspective, Regional Studies 33, 143-156.

RICE, P. and A.J. VENABLES (2004) Spatial determinants of productivity: analysis for the regions of Great Britain, Centre for Economic Performance Paper, CEPDP0642, London, Centre for Economic Performance, LSE. 
1 ROBERTS, M. (2004) The growth performance of GB counties: Some new empirical evidence for 
Table 1: Income, Earnings and Productivity - Summary Statistics

(Bracketed term: excluding Inner London - East and West)

\begin{tabular}{|c|c|c|c|c|c|}
\hline & $\begin{array}{c}\text { GVA per } \\
\text { (employee) } \\
\text { hour worked } \\
g_{i} \\
\end{array}$ & $\begin{array}{c}\text { Average } \\
\text { hourly } \\
\text { earnings } \\
e_{i} \\
\end{array}$ & $\begin{array}{l}\text { Composition } \\
\text { index, } c_{i} \\
\text { (9 major } \\
\text { groups) }\end{array}$ & $\begin{array}{l}\text { Productivity } \\
\text { index, } q_{i} \\
(9 \text { major } \\
\text { groups } \\
\end{array}$ & $\begin{array}{l}\text { Productivity } \\
\text { index, } q_{i} \\
\text { (38 groups) }\end{array}$ \\
\hline Mean $(£)$ & $\begin{array}{c}18.66 \\
(18.58)\end{array}$ & $\begin{array}{c}9.82 \\
(9.71)\end{array}$ & $\begin{array}{c}10.17 \\
(10.15)\end{array}$ & $\begin{array}{c}9.93 \\
(9.86)\end{array}$ & $\begin{array}{c}9.57 \\
(9.51)\end{array}$ \\
\hline Variance & $\begin{array}{c}3.71 \\
(3.28)\end{array}$ & $\begin{array}{l}1.66 \\
(0.97)\end{array}$ & $\begin{array}{c}0.22 \\
(0.19)\end{array}$ & $\begin{array}{c}0.76 \\
(0.47)\end{array}$ & $\begin{array}{c}0.62 \\
(0.40)\end{array}$ \\
\hline $\begin{array}{l}\text { Coefficient of } \\
\text { variation }\end{array}$ & $\begin{array}{c}0.1032 \\
(0.0974)\end{array}$ & $\begin{array}{c}0.1314 \\
(0.1016)\end{array}$ & $\begin{array}{c}0.0460 \\
(0.0420)\end{array}$ & $\begin{array}{c}0.0878 \\
(0.0697) \\
\end{array}$ & $\begin{array}{c}0.0823 \\
(0.0667) \\
\end{array}$ \\
\hline Minimum & 14.79 & 7.79 & 9.12 & 8.47 & 8.31 \\
\hline Maximum & $\begin{array}{c}25.20 \\
(24.18) \\
\end{array}$ & $\begin{array}{c}17.54 \\
(13.16) \\
\end{array}$ & $\begin{array}{c}12.03 \\
(11.35) \\
\end{array}$ & $\begin{array}{c}14.53 \\
(11.90) \\
\end{array}$ & $\begin{array}{c}13.52 \\
(11.45) \\
\end{array}$ \\
\hline \multicolumn{6}{|c|}{ Correlation coefficients } \\
\hline$\overline{\mathrm{GVA}}, g_{i}$ & 1.00 & $\begin{array}{c}0.7610 \\
(0.7414)\end{array}$ & $\begin{array}{c}0.6695 \\
(0.6148)\end{array}$ & $\begin{array}{c}0.7207 \\
(0.6812)\end{array}$ & $\begin{array}{c}0.7217 \\
(0.6798)\end{array}$ \\
\hline Earnings, $e_{i}$ & & 1.00 & $\begin{array}{c}0.8202 \\
(0.8077) \\
\end{array}$ & $\begin{array}{c}0.9638 \\
(0.9450) \\
\end{array}$ & $\begin{array}{c}0.9569 \\
(0.9387) \\
\end{array}$ \\
\hline $\begin{array}{l}\text { Composition } \\
\text { index, } c_{i}\end{array}$ & & & 1.00 & $\begin{array}{c}0.6573 \\
(0.5801) \\
\end{array}$ & $\begin{array}{c}0.6767 \\
(0.6077) \\
\end{array}$ \\
\hline $\begin{array}{l}\text { Productivity } \\
\text { index, } q_{i}(9)\end{array}$ & & & & 1.00 & $\begin{array}{c}0.9875 \\
(0.9807) \\
\end{array}$ \\
\hline
\end{tabular}


Table 2: Measures of Global Spatial Autocorrelation

\begin{tabular}{|c|c|c|c|c|c|c|c|c|}
\hline & \multicolumn{4}{|c|}{ GVA per (employee) hour worked } & \multicolumn{4}{|c|}{ Average hourly earnings } \\
\hline \multicolumn{9}{|c|}{ Moran's I test - Spatial weight matrix: estimated travel time $\leq \mathrm{d}$ minutes } \\
\hline $\mathrm{d}$ & I & $\mathrm{z}(\mathrm{I})$ & p1 & $\mathrm{p} 2$ & I & $\mathrm{z}(\mathrm{I})$ & p1 & $\mathrm{p} 2$ \\
\hline 30 & 0.6034 & 7.8324 & 0.0000 & 0.0001 & 0.5949 & 7.7233 & 0.0000 & 0.0001 \\
\hline 60 & 0.3496 & 7.3830 & 0.0000 & 0.0001 & 0.4208 & 8.8515 & 0.0000 & 0.0001 \\
\hline 90 & 0.2609 & 8.0003 & 0.0000 & 0.0001 & 0.3224 & 9.8283 & 0.0000 & 0.0001 \\
\hline 120 & 0.1718 & 7.3745 & 0.0000 & 0.0001 & 0.2113 & 8.9931 & 0.0000 & 0.0001 \\
\hline 150 & 0.0920 & 5.1837 & 0.0000 & 0.0003 & 0.1241 & 6.8397 & 0.0000 & 0.0004 \\
\hline 180 & 0.0556 & 3.8419 & 0.0001 & 0.0036 & 0.0693 & 4.6616 & 0.0000 & 0.0017 \\
\hline \multicolumn{9}{|c|}{ Geary's c test - Spatial weight matrix: estimated travel time $\leq \mathrm{d}$ minutes } \\
\hline $\mathrm{d}$ & $\mathrm{c}$ & $z(c)$ & p1 & $\mathrm{p} 2$ & $\mathrm{c}$ & $\mathrm{z}(\mathrm{c})$ & p1 & p2 \\
\hline 30 & 0.5208 & -4.3783 & 0.0000 & 0.0001 & 0.6048 & -3.6106 & 0.0003 & 0.0374 \\
\hline 60 & 0.6739 & -5.6034 & 0.0000 & 0.0001 & 0.6636 & -5.7802 & 0.0000 & 0.0057 \\
\hline 90 & 0.7614 & -5.7480 & 0.0000 & 0.0001 & 0.7361 & -6.3579 & 0.0000 & 0.0082 \\
\hline 120 & 0.8507 & -4.3763 & 0.0000 & 0.0007 & 0.8350 & -4.8359 & 0.0000 & 0.0145 \\
\hline 150 & 0.9349 & -2.1293 & 0.0332 & 0.0413 & 0.9247 & -2.4658 & 0.0137 & 0.1064 \\
\hline 180 & 0.9786 & -0.8444 & 0.3984 & 0.2209 & 0.9591 & -1.6158 & 0.1061 & 0.2177 \\
\hline
\end{tabular}


Table 3: Measures of Global Spatial Autocorrelation

\begin{tabular}{|c|c|c|c|c|c|c|c|c|}
\hline & \multicolumn{4}{|c|}{ Productivity index } & \multicolumn{4}{|c|}{ Occupational composition index } \\
\hline \multicolumn{9}{|c|}{ Moran's I test - Spatial weight matrix: estimated travel time $\leq \mathrm{d}$ minutes } \\
\hline $\mathrm{d}$ & I & $\mathrm{z}(\mathrm{I})$ & $\mathrm{p} 1$ & $\mathrm{p} 2$ & I & $\mathrm{z}(\mathrm{I})$ & $\mathrm{p} 1$ & $\mathrm{p} 2$ \\
\hline 30 & 0.6171 & 8.0081 & 0.0000 & 0.0001 & 0.3451 & 4.5258 & 0.0000 & 0.0001 \\
\hline 60 & 0.4386 & 9.2183 & 0.0000 & 0.0001 & 0.2655 & 5.6493 & 0.0000 & 0.0001 \\
\hline 90 & 0.3410 & 10.3798 & 0.0000 & 0.0001 & 0.2276 & 7.0128 & 0.0000 & 0.0001 \\
\hline 120 & 0.2323 & 9.8524 & 0.0000 & 0.0001 & 0.1454 & 6.2976 & 0.0000 & 0.0001 \\
\hline 150 & 0.1331 & 7.3044 & 0.0000 & 0.0002 & 0.0963 & 5.4050 & 0.0000 & 0.0004 \\
\hline 180 & 0.0692 & 4.6564 & 0.0000 & 0.0013 & 0.0513 & 3.5827 & 0.0003 & 0.0043 \\
\hline \multicolumn{9}{|c|}{ Geary's c test - Spatial weight matrix: estimated travel time $\leq \mathrm{d}$ minutes } \\
\hline d & $\mathrm{c}$ & $\mathrm{z}(\mathrm{c})$ & $\mathrm{p} 1$ & $\mathrm{p} 2$ & $\mathrm{C}$ & $\mathrm{z}(\mathrm{c})$ & $\mathrm{p} 1$ & $\mathrm{p} 2$ \\
\hline 30 & 0.5293 & -4.3008 & 0.0000 & 0.0020 & 0.7992 & -1.8350 & 0.0665 & 0.0623 \\
\hline 60 & 0.6226 & -6.4845 & 0.0000 & 0.0004 & 0.7932 & -3.5527 & 0.0004 & 0.0024 \\
\hline 90 & 0.6985 & -7.2623 & 0.0000 & 0.0004 & 0.8080 & -4.6254 & 0.0000 & 0.0007 \\
\hline 120 & 0.7945 & -6.0223 & 0.0000 & 0.0048 & 0.8822 & -3.4534 & 0.0005 & 0.0067 \\
\hline 150 & 0.8911 & -3.5661 & 0.0004 & 0.0282 & 0.9401 & -1.9611 & 0.0499 & 0.0619 \\
\hline 180 & 0.9410 & -2.3329 & 0.0197 & 0.0883 & 0.9692 & -1.2167 & 0.2237 & 0.1568 \\
\hline
\end{tabular}


1

2

3

4

5

6

7

8

9

10

11

12

13

14

15

16

17

18

19

20

21

22

23

24

25

26

27

28

29

30

31

32

33

34

35

36

37

38

39

40

41

42

43

44

45

46

47

48

49

50

51

52

53

54

55

56

57

58

59

60

${ }^{1}$ For further discussion see Fujita and Thisse (2002).

${ }^{2}$ Examples of this approach applied to UK data can be found in Fingleton (2001) and (2003).

${ }^{3}$ The Nomenclature of Territorial Units for Statistics (NUTS) was established by the Statistical Office of the European

Communities (Eurostat) to provide a single uniform breakdown of territorial units for the production of EU regional

statistics. Great Britain is divided into 10 regions at the NUTS1 level, and 126 areas at the NUTS3 level. For example the area of Greater London is made up of 5 NUTS3 areas.

$\mid{ }^{4}$ In the absence of sub-regional price deflators, we are only able to look at nominal income.

Deleted:

${ }^{5}$ For further discussion of the theoretical basis for this assertion see Rice and Venables. (2004), pp. 8-10.

${ }^{6}$ Given the decomposition $e_{i}=q_{i}+c_{i}+r_{i}$, the contribution of the productivity index $\left(q_{i}\right)$ to the spatial variation in earnings $\left(e_{i}\right)$ is measured by $\left[\operatorname{var}\left(q_{i}\right)+\operatorname{cov}\left(q_{i}, c_{i}+r_{i},\right)\right] / \operatorname{var}\left(e_{i}\right)$ (i.e. the share of the variance of $q_{i}$ plus its covariance in the total variance of $e_{i}$ ) and is equal in value to the slope coefficient of the simple regression of the productivity index $\left(q_{i}\right)$ on earnings $\left(e_{i}\right)$.

${ }^{7}$ Travel times between the NUTS 3 areas are estimated using Microsoft Autoroute 2002. The Microsoft Autoroute software computes the driving time between two locations on the basis of the most efficient route given the road network in 2002, and allowing for different average speeds of travel depending on the type of road.

${ }^{8}$ The persistence of the correlation over several lags may be indicative of non-stationarity in the area data; e.g. the presence of a simple trend in space analogous to a time trend in time-series data

9 The results of the outliers analysis are available upon request For an application of these techniques in a similar context see Ertur and Le Gallo, 2003

${ }^{10}$ An alternative approach of dividing the p-value by the average number of neighbours (i.e.,20.15) produces similar evidence as using the Bonferroni bound.

${ }^{11}$ The only three unconnected observations, namely Aberdeen, Cumbria and Highlands, have been linked to the relative

Deleted: For the statistical test Deleted: see Deleted: Table A1 in Appendix 3) Deleted: ( Deleted: ) Deleted: leads in our case roughly to the same evidence

closest area in terms of travel time (i.e. Durham, Angus - Dundee City, Perth - Kinross - Stirling respectively). The average number of links is 20.15 , the percentage of non-zero weights is 17.08 .

${ }^{12}$ As noted above, the pseudo-significance levels obtained by the conditional randomisation approach are identical for the Getis-Ord's G and local Moran's I statistics. Figures showing the NUTS3 areas for which the local statistics are $\underline{\text { significant using the far more conservative criteria of } 0.00043 \text { implied by the Bonferroni procedure are available upon }}$ $\underline{\text { request. }}$

${ }^{13}$ The results of the robustness analysis using transition matrices are available upon request.

${ }^{14}$ Once again Inner London (west) emerges as a possible outlier in respect of the productivity index but there is no evidence that this observation is unduly influencing the results (results available upon request). 
${ }^{15}$ These findings are robust with respect to the choice of the spatial weight matrix (results available upon request). 
All data is at the level of the 126 NUTS 3 areas of Great Britain. Because of missing or inadequate information on our target variables, the following NUTS 3 areas are aggregated: East Cumbria and West Cumbria; South and West Derbyshire and East Derbyshire; North Nottinghamshire and South Nottinghamshire; Isle of Anglesey and Gwynedd; Caithness, Sutherland and Ross \& Cromarty, Inverness and Nairn \& Moray, Badenoch \& Strathspey, Lochaber, Sky, Lochalsh \& Argyll and the Islands. The Western Isles, Orkney Islands and Shetland Islands are excluded from the sample. Unless otherwise stated, the data relate to the period 1998 to 2001, and the four years of data are averaged to remove short-run volatility.

GVA per (employee) hour worked $\left(g_{i}\right)$ : Estimates of workplace-based gross value added at basic prices are from the Office of National Statistics (2003). ONS estimates of GVA are computed using the income approach. Estimates of the main components of income - wages and salaries for employees, self-employment income and gross trading profits - based on the location of the workplace are derived from a range of sources including the Annual Business Inquiry, New Earnings Survey and the Inland Revenue Survey of Personal Income. The remaining components such as rental income are apportioned to a given area using a wages and salaries indicator. For further details see Office of National Statistics (2003).

Total hours worked by employees is computed from data on the numbers of full-time employees and of part-time employees and the average weekly hours worked by each group taken from the Annual Business Inquiry.

Average hourly earnings $\left(e_{i}\right)$ : Estimates of the average hourly earnings of all full-time employees whose pay was not affected by absence at the NUTS 3 level based on the location of workplace are taken from the New Earnings Surveys for the appropriate years.

Productivity index $\left(q_{i}=\Sigma_{k} w_{i}^{k} \bar{\lambda}^{k}\right)$ : Weighted sum of the average earnings of each occupational group in area $i$, with weights equal to the share of the occupational group in total GB employment. Data on average hourly earnings of full-time employees at the level of the occupational major group and at the two digit occupational level from the New Earnings Survey. The weights are computed from data on the share of 2-digit occupations in total GB employment from the Labour Force Survey 2001.

Composition index $\left(c_{i}=\Sigma_{k} \bar{w}^{k} \lambda_{i}^{k}\right)$ : Weighted sum of the shares of each occupational major group in employment in area $i$, with weights equal to the GB average earnings of the occupational major group. Estimates of occupational shares in employment are derived from the Labour Force Survey for the appropriate years. Labour Force Survey data is residence-based, rather than workplace Exploratory Spatial Data Analysis II II measured on a continuous scale, the measurement of global spatial autocorrelation is usually based on Moran's $I$ and Geary's $c$ statistics (Cliff and Ord, 1981). II

Moran's $I$ is defined as II

$I=\frac{n}{S_{0}} \frac{\sum_{i} \sum_{j} w_{i j}\left(x_{i}-\bar{x}\right)\left(x_{j}-\right.}{\sum_{i}\left(x_{i}-\bar{x}\right)^{2}}$

(1)पI

where $n$ is the number of observations,

$x_{i}$ denotes the observation at site $i$ for

the variable of interest $X$, and $w_{i j}$

denotes the elements of the spatial weights matrix. $S_{0}$ is a scaling factor equal to the sum of all the elements in the weight matrix. The spatial weight matrix may be row-standardised such that the

elements $\tilde{w}_{i j}$ in each row sum to 1 in

order to normalise the size of the neighbourhood set for each site. In this case $S_{0}=\mathrm{n}$ and the expression (1)

simplifies to a ratio of the spatial crossproduct to the variance. Moran's $I$ is a cross product coefficient scaled to be less than one in value, with an expected value $E(I)=-1 /(n-1) \approx 0$ for $n$ sufficiently large. Values for Moran's $I$ larger (smaller) than the expected value indicate positive

(negative) spatial correlation.II

An alternative measure of global spatial autocorrelation is given by Geary's $c$ coefficient which is based on squared deviations. Geary's $c$ is defined as II

$c=\frac{(n-1)}{2 S_{0}} \frac{\sum_{i} \sum_{j} w_{i j}\left(x_{i}-x_{j}\right)}{\sum_{i}\left(x_{i}-\bar{x}\right)^{2}}$ (2) 9

The expected value for Geary's $\mathrm{c}$ is 1 . Values of Geary's $c$ less than one indicate positive spatial correlation, while values larger than one suggest negative spatial correlation. II

Inference is typically based on a standardised z-value of the statistic computed by subtracting the expected value and dividing by the standard deviation in the usual way. Assuming that the variable of interest is normally distributed, the z-value follows a standard normal distribution, and the significance of the test statistic may be judged by comparing the computed $z$-value with its probability in the standard normal tables (for a theoretical discussion and detailed expressions for the moments of the (asymptotic) distributions of $I$ and $c$ under various assumptions, see $\mathrm{Cl}$... [1]

Deleted: 2

Deleted: To achieve a consistent data set 
based, and this, coupled with the fact that the data is available only for the major occupational groups, limits comparability with the productivity index. Weights are computed from data on the GB average hourly earnings by major occupational group from the New Earnings Survey.

Travel times: Driving times between the population centres of NUTS 3 areas, are estimated using Microsoft Autoroute 2002. The Microsoft Autoroute software computes the estimated driving time between two locations on the basis of the most efficient route given the road network in 2002, and allowing for different average speeds of travel depending on the type of road. In general the average speeds are set at the upper limit for road type, namely $70 \mathrm{mph}$ for motorways, $60 \mathrm{mph}$ for other highways; $40 \mathrm{mph}$ for major roads, 30mph for minor roads and $18 \mathrm{mph}$ for streets within urban areas.

\section{Appendix 2: Additional Tables}

TABLE A1: Measures of global spatial autocorrelation for average hourly earnings

Deleted: 2 ( Inner-London-West excluded from sample)

\begin{tabular}{|c|c|c|c|c|}
\hline \multicolumn{5}{|c|}{ Moran's I test - spatial weight matrix: estimated travel time $<d$ minutes } \\
\hline$d$ & $I$ & $z(I)$ & pl & $p 2$ \\
\hline 30 & 0.5501 & 7.0313 & 0.0000 & 0.0001 \\
\hline 60 & 0.4321 & 8.9909 & 0.0000 & 0.0001 \\
\hline 90 & 0.3494 & 10.5236 & 0.0000 & 0.0001 \\
\hline 120 & 0.2293 & 9.6311 & 0.0000 & 0.0001 \\
\hline 150 & 0.1467 & 7.9229 & 0.0000 & 0.0002 \\
\hline 180 & 0.0767 & 5.0609 & 0.0000 & 0.0012 \\
\hline \multicolumn{5}{|c|}{ Geary's c test - spatial weight matrix: estimated travel time $<d$ minutes } \\
\hline$d$ & $c$ & $z(c)$ & pl & $p 2$ \\
\hline 30 & 0.5379 & -4.1575 & 0.0000 & 0.0008 \\
\hline 60 & 0.6307 & -6.2815 & 0.0000 & 0.0057 \\
\hline 90 & 0.6899 & -7.3973 & 0.0000 & 0.0082 \\
\hline 120 & 0.8060 & -5.6378 & 0.0000 & 0.0009 \\
\hline 150 & 0.8820 & -3.8230 & 0.0001 & 0.0147 \\
\hline 180 & 0.9417 & -2.2780 & 0.0227 & 0.0595 \\
\hline
\end{tabular}


TABLE A2; Local Spatial Correlation Statistics*

\begin{tabular}{|c|c|c|c|c|c|c|c|c|c|c|}
\hline \multirow[b]{3}{*}{ NUTS3 area } & \multicolumn{5}{|c|}{ GVA per (employee) hour worked } & \multicolumn{5}{|c|}{ Average hourly earnings } \\
\hline & \multicolumn{2}{|c|}{ Getis Ord } & \multicolumn{3}{|c|}{ Local Moran's I } & \multicolumn{2}{|c|}{ Getis Ord } & \multicolumn{3}{|c|}{ Local Moran I } \\
\hline & $G_{i}$ & p1 & $z\left(I_{i}\right)$ & p1 & p2 & $\boldsymbol{G}_{\boldsymbol{i}}$ & p1 & $z\left(I_{i}\right)$ & p1 & p2 \\
\hline \multicolumn{11}{|l|}{ NORTH EAST } \\
\hline Hartlepool and Stockton-on-Tees & -1.9743 & 0.0483 & 0.4825 & 0.6295 & 0.0220 & -2.1016 & 0.0356 & 0.7615 & 0.4464 & 0.0519 \\
\hline South Teesside & -2.0240 & 0.0430 & 1.4228 & 0.1548 & 0.0390 & -2.2653 & 0.0235 & 0.4317 & 0.6660 & 0.0709 \\
\hline Darlington & -1.9720 & 0.0486 & 1.8954 & 0.0580 & 0.0230 & -2.0517 & 0.0402 & 1.4743 & 0.1404 & 0.0549 \\
\hline Durham CC & -2.0201 & 0.0434 & 0.9113 & 0.3621 & 0.0285 & -2.1054 & 0.0305 & 0.8437 & 0.3988 & $\mathbf{0 . 0 3 3 0}$ \\
\hline Northumberland & -2.1464 & 0.0318 & 1.5079 & 0.1316 & 0.0070 & -2.4646 & 0.0137 & 1.5508 & 0.1209 & 0.0060 \\
\hline Tyneside & -2.0810 & 0.0374 & 1.4865 & 0.1371 & 0.0320 & -2.3194 & 0.0204 & 0.6688 & 0.5036 & 0.0290 \\
\hline Sunderland & -2.2398 & 0.0251 & 1.4474 & 0.1478 & 0.0488 & -1.9743 & 0.0483 & 0.8985 & 0.3689 & 0.0859 \\
\hline \multicolumn{11}{|l|}{ NORTH WEST } \\
\hline Cumbria & -2.5453 & 0.0109 & 1.6031 & 0.1089 & 0.0030 & -2.2323 & 0.0256 & 0.8099 & 0.4180 & 0.0470 \\
\hline Halton and Warrington & -3.3348 & 0.0009 & 1.4824 & 0.1382 & 0.0001 & -0.9093 & 0.3632 & -0.1167 & 0.9071 & 0.1628 \\
\hline Cheshire CC & -3.4567 & 0.0005 & -4.4379 & 0.0000 & 0.0001 & -0.8130 & 0.4162 & -0.8086 & 0.4187 & 0.0338 \\
\hline Greater Manchester South & -3.2489 & 0.0012 & 0.1868 & 0.8518 & 0.0020 & -1.9894 & 0.0467 & -0.7185 & 0.4724 & 0.0470 \\
\hline Greater Mancl & -3.6121 & 0.0003 & 2.7621 & 0.0057 & 0.0001 & -2.0660 & 0.0388 & 0.9307 & 0.3520 & 0.0150 \\
\hline Blackburn with Darwen & -3.6540 & 0.0003 & 4.5314 & 0.0000 & 0.0001 & -2.2050 & 0.0275 & 1.1428 & 0.2531 & 0.0410 \\
\hline Blackpool & -2.8554 & 0.0043 & 4.6547 & 0.0000 & 0.0030 & -0.8837 & 0.3768 & 0.9380 & 0.3483 & 0.1888 \\
\hline Lancashire CC & -2.9256 & 0.0034 & 0.9580 & 0.3381 & 0.0001 & -1.8575 & 0.0632 & 0.0039 & 0.9969 & 0.0749 \\
\hline East Merseyside & -3.3615 & 0.0008 & 3.6716 & 0.0002 & 0.0001 & -1.1063 & 0.2686 & -0.2086 & 0.8348 & 0.1219 \\
\hline Liverpool & -3.4931 & 0.0005 & 2.7573 & 0.0058 & 0.0001 & -1.1185 & 0.2634 & -0.1134 & 0.9097 & 0.1259 \\
\hline Sefton & -2.8885 & 0.0039 & 3.6875 & 0.0002 & 0.0001 & -1.0236 & 0.3060 & 0.4678 & 0.6400 & 0.1379 \\
\hline Wirral & -3.7059 & 0.0002 & 3.8252 & 0.0001 & 0.0001 & -0.9571 & 0.3385 & 0.1340 & 0.8934 & 0.1658 \\
\hline \multicolumn{11}{|c|}{ YORKSHIRE AND HUMBERSIDE } \\
\hline Kingston upon Hull, City of & -0.6084 & 0.5429 & 0.6029 & 0.5466 & 0.2687 & -1.1948 & 0.2322 & 1.3093 & 0.1904 & 0.0909 \\
\hline East Riding of Yorkshire & -1.0709 & 0.2842 & -1.1031 & 0.2700 & 0.1259 & -1.3370 & 0.1812 & 0.6090 & 0.5425 & 0.0589 \\
\hline North and N E Lincolnshire & -1.2171 & 0.2236 & -0.2430 & 0.8080 & 0.1009 & -1.5537 & 0.1203 & 1.3015 & 0.1931 & 0.0760 \\
\hline York & -2.2397 & 0.0251 & -0.0571 & 0.9544 & 0.0120 & -2.0240 & 0.0430 & -0.1461 & 0.8838 & 0.0280 \\
\hline North Yorkshire CC & -2.7163 & 0.0066 & -0.0352 & 0.9720 & 0.0020 & -2.3194 & 0.0204 & -0.3151 & 0.7527 & 0.0200 \\
\hline Barnsley, Doncaster, Rotherham & -1.7866 & 0.0740 & 2.4241 & 0.0153 & 0.0300 & -1.0226 & 0.3065 & 1.0724 & 0.2835 & 0.1558 \\
\hline Sheffield & -1.6065 & 0.1082 & 1.1692 & 0.2423 & 0.0519 & -0.8094 & 0.4183 & 0.0139 & 0.9889 & 0.2078 \\
\hline Bradford & -2.7535 & 0.0059 & 2.2371 & 0.0253 & 0.0001 & -1.9720 & 0.0486 & 1.0713 & 0.2840 & 0.0270 \\
\hline Leeds & -3.0842 & 0.0020 & 0.6545 & 0.5128 & 0.0001 & -2.0133 & 0.0441 & -0.1071 & 0.9147 & 0.0120 \\
\hline Calderdale, Kirklees.Wakefield & -3.0971 & 0.0020 & 1.3543 & 0.1756 & 0.0001 & -2.1233 & 0.0337 & 0.2559 & 0.7981 & 0.0101 \\
\hline
\end{tabular}


TABLE A2: Local Spatial Correlation Statistics

\begin{tabular}{|c|c|c|c|c|c|c|c|c|c|c|}
\hline \multirow[b]{3}{*}{ NUTS3 area } & \multicolumn{5}{|c|}{ GVA per (employee) hour worked } & \multicolumn{5}{|c|}{ Average hourly earnings } \\
\hline & \multicolumn{2}{|c|}{ Getis Ord } & \multicolumn{2}{|c|}{ Local Moran's I } & \multirow[b]{2}{*}{ p2 } & \multicolumn{2}{|c|}{ Getis Ord } & \multicolumn{2}{|c|}{ Local Moran I } & \multirow[b]{2}{*}{$p 2$} \\
\hline & $\boldsymbol{G}_{\boldsymbol{i}}$ & $p 1$ & $z\left(I_{i}\right)$ & p1 & & $\boldsymbol{G}_{\boldsymbol{i}}$ & $p 1$ & $z\left(I_{i}\right)$ & p1 & \\
\hline \multicolumn{11}{|l|}{ EAST MIDLANDS } \\
\hline Derby & -1.4595 & 0.1444 & -1.8269 & 0.0677 & 0.0599 & -0.4502 & 0.6525 & -0.1350 & 0.8926 & 0.3487 \\
\hline Derbyshire & -1.7355 & 0.0827 & 0.7561 & 0.4496 & 0.0530 & -0.7223 & 0.4701 & 0.2744 & 0.7838 & 0.2368 \\
\hline Nottingham & -1.1985 & 0.2307 & 0.1858 & 0.8526 & 0.1069 & -0.6652 & 0.5059 & 0.3749 & 0.7077 & 0.2527 \\
\hline Nottinghamshire & -1.4116 & 0.1581 & -0.5943 & 0.5523 & 0.0789 & -1.1820 & 0.2372 & 0.2625 & 0.7929 & 0.1169 \\
\hline Leicester & 1.0880 & 0.2766 & -0.8740 & 0.3821 & 0.1429 & -1.9508 & 0.0511 & -2.1468 & 0.0318 & 0.0160 \\
\hline Leicestershire CC and Rutland & -0.7468 & 0.4552 & -0.3132 & 0.7541 & 0.2248 & -0.2487 & 0.8036 & 0.0314 & 0.9750 & 0.4236 \\
\hline Northamptonshire & 3.5503 & 0.0004 & 1.5492 & 0.1213 & 0.0001 & 4.6307 & 0.0000 & 0.1091 & 0.9132 & 0.0001 \\
\hline Lincolnshire & -0.4116 & 0.6806 & 0.1651 & 0.8689 & 0.3277 & -1.3850 & 0.1661 & 1.2779 & 0.2013 & 0.0870 \\
\hline \multicolumn{11}{|l|}{ WEST MIDLANDS } \\
\hline Herefordshire, County of & -0.6231 & 0.5332 & 0.3372 & 0.7360 & 0.2727 & -0.3140 & 0.7535 & 0.3208 & 0.7484 & 0.4236 \\
\hline Worcestershire & 1.2271 & 0.2198 & -0.9134 & 0.3611 & 0.1319 & 1.4855 & 0.1374 & -0.3422 & 0.7322 & 0.0859 \\
\hline Warwickshire & 2.8078 & 0.0050 & 1.6238 & 0.1044 & 0.0070 & 3.5460 & 0.0004 & 2.1943 & 0.0282 & 0.0001 \\
\hline Telford and Wrekin & -1.6480 & 0.0994 & 2.2125 & 0.0269 & 0.0550 & -0.1822 & 0.8554 & 0.1537 & 0.8778 & 0.4486 \\
\hline Shropshire CC & -1.1869 & 0.2353 & 0.9590 & 0.3376 & 0.0979 & -0.6436 & 0.5198 & 0.2280 & 0.8197 & 0.2737 \\
\hline Stoke-on-Trent & -2.6670 & 0.0077 & 5.1602 & 0.0000 & 0.0020 & -0.6644 & 0.5065 & 0.9062 & 0.3648 & 0.2488 \\
\hline Staffordshire CC & -1.7538 & 0.0795 & 1.4644 & 0.1431 & 0.0570 & -0.0555 & 0.9558 & 0.0719 & 0.9427 & 0.4815 \\
\hline Birmingham & 0.7039 & 0.4815 & -0.0687 & 0.9453 & 0.2527 & 2.3396 & 0.0193 & 1.5699 & 0.1164 & 0.0110 \\
\hline Solihull & 1.7905 & 0.0734 & 0.0587 & 0.9532 & 0.0390 & 3.1917 & 0.0014 & 3.7016 & 0.0002 & 0.0001 \\
\hline Coventry & 1.7812 & 0.0749 & 1.3013 & 0.1931 & 0.0310 & 3.1283 & 0.0018 & 1.8684 & 0.0617 & 0.0001 \\
\hline Dudley and Sandwell & 0.3673 & 0.7134 & -0.4382 & 0.6613 & 0.4086 & 1.0447 & 0.2962 & -0.6027 & 0.5467 & 0.1628 \\
\hline Walsall and Wolverhampton & -1.4061 & 0.1597 & 1.4126 & 0.1578 & 0.0629 & 0.1398 & 0.8888 & -0.0551 & 0.9561 & 0.4406 \\
\hline \multicolumn{11}{|l|}{ EAST } \\
\hline Peterborough & 2.3719 & 0.0177 & -1.9094 & 0.0562 & 0.0110 & 2.0517 & 0.0402 & 0.2061 & 0.8367 & 0.0759 \\
\hline Cambridgeshire CC & 4.2114 & 0.0000 & 3.3262 & 0.0009 & 0.0001 & 4.5379 & 0.0000 & 4.7235 & 0.0000 & 0.0001 \\
\hline Norfolk & -0.8324 & 0.4052 & 0.2376 & 0.8122 & 0.2138 & -0.3295 & 0.7418 & 0.1802 & 0.8570 & 0.4186 \\
\hline Suffolk & 1.8479 & 0.0646 & -0.6707 & 0.5024 & 0.0410 & 1.4929 & 0.1355 & -0.8515 & 0.3945 & 0.0909 \\
\hline Luton & 4.6471 & 0.0000 & 4.7175 & 0.0000 & 0.0001 & 5.9200 & 0.0000 & 2.7687 & 0.0056 & 0.0001 \\
\hline Bedfordshire CC & 4.6879 & 0.0000 & 4.3188 & 0.0000 & 0.0001 & 5.6646 & 0.0000 & 4.0528 & 0.0001 & 0.0001 \\
\hline Hertfordshire & 4.9516 & 0.0000 & 9.5087 & 0.0000 & 0.0001 & 6.2600 & 0.0000 & 10.4383 & 0.0000 & 0.0001 \\
\hline Southend-on-Sea & 5.4217 & 0.0000 & -0.8032 & 0.4219 & 0.0001 & 6.0924 & 0.0000 & -0.6357 & 0.5250 & 0.0001 \\
\hline Thurrock & 5.4694 & 0.0000 & 9.0834 & 0.0000 & 0.0001 & 6.2459 & 0.0000 & 2.8865 & 0.0039 & 0.0001 \\
\hline Essex CC & 5.7496 & 0.0000 & 3.4163 & 0.0006 & 0.0001 & 6.4316 & 0.0000 & 3.9092 & 0.0001 & 0.0001 \\
\hline
\end{tabular}


TABLE A2: Local Spatial Correlation Statistics

\begin{tabular}{|c|c|c|c|c|c|c|c|c|c|c|}
\hline \multirow[b]{3}{*}{ NUTS3 area } & \multicolumn{5}{|c|}{ GVA per (employee) hour worked } & \multicolumn{5}{|c|}{ Average hourly earnings } \\
\hline & \multicolumn{2}{|c|}{ Getis Ord } & \multicolumn{2}{|c|}{ Local Moran's I } & \multirow[b]{2}{*}{$p 2$} & \multicolumn{2}{|c|}{ Getis Ord } & \multicolumn{2}{|c|}{ Local Moran I } & \multirow[b]{2}{*}{$p 2$} \\
\hline & $G_{i}$ & p1 & $z\left(I_{i}\right)$ & p1 & & $\boldsymbol{G}_{\boldsymbol{i}}$ & p1 & $z\left(I_{i}\right)$ & p1 & \\
\hline \multicolumn{11}{|l|}{ LONDON } \\
\hline Inner London - West & 5.5528 & 0.0000 & 17.5800 & 0.0000 & 0.0001 & 6.8816 & 0.0000 & 33.9408 & 0.0000 & 0.0001 \\
\hline Inner London - East & 5.8535 & 0.0000 & 11.4038 & 0.0000 & 0.0001 & 6.3619 & 0.0000 & 22.3287 & 0.0000 & 0.0001 \\
\hline Outer London - East and NE & 5.5813 & 0.0000 & 4.0448 & 0.0001 & 0.0001 & 6.2284 & 0.0000 & 3.6520 & 0.0003 & 0.0001 \\
\hline Outer London - South & 5.8925 & 0.0000 & 4.1391 & 0.0000 & 0.0001 & 6.4050 & 0.0000 & 8.2618 & 0.0000 & 0.0001 \\
\hline Outer London - West and NW & 5.1358 & 0.0000 & 12.7564 & 0.0000 & 0.0001 & 6.0581 & 0.0000 & 13.6382 & 0.0000 & 0.0001 \\
\hline \multicolumn{11}{|l|}{ SOUTH EAST } \\
\hline Berkshire & 5.5693 & 0.0000 & 15.1784 & 0.0000 & 0.0001 & 6.2977 & 0.0000 & 14.5421 & 0.0000 & 0.0001 \\
\hline Milton Keynes & 4.0335 & 0.0001 & 3.3265 & 0.0009 & 0.0001 & 5.2221 & 0.0000 & 4.9983 & 0.0000 & 0.0001 \\
\hline Buckinghamshire CC & 5.5158 & 0.0000 & 13.3499 & 0.0000 & 0.0001 & 6.5328 & 0.0000 & 13.3738 & 0.0000 & 0.0001 \\
\hline Oxfordshire & 5.1405 & 0.0000 & 5.7871 & 0.0000 & 0.0001 & 5.7668 & 0.0000 & 6.8417 & 0.0000 & 0.0001 \\
\hline Brighton and Hove & 5.2022 & 0.0000 & -1.9719 & 0.0486 & 0.0001 & 5.8707 & 0.0000 & 3.6247 & 0.0003 & 0.0001 \\
\hline East Sussex CC & 4.1851 & 0.0000 & 0.7904 & 0.4293 & 0.0001 & 5.6519 & 0.0000 & -3.0916 & 0.0020 & 0.0001 \\
\hline Surrey & 5.7886 & 0.0000 & 12.5129 & 0.0000 & 0.0001 & 6.2644 & 0.0000 & 16.2595 & 0.0000 & 0.0001 \\
\hline West Sussex & 4.3061 & 0.0000 & 2.7113 & 0.0067 & 0.0001 & 5.4583 & 0.0000 & 3.5740 & 0.0004 & 0.0001 \\
\hline Portsmouth & 4.7795 & 0.0000 & -2.2289 & 0.0258 & 0.0001 & 5.8527 & 0.0000 & 0.7856 & 0.4321 & 0.0001 \\
\hline Southampton & 5.6638 & 0.0000 & 0.1889 & 0.8502 & 0.0001 & 6.3029 & 0.0000 & 1.2213 & 0.2220 & 0.0001 \\
\hline Hampshire CC & 5.5521 & 0.0000 & 3.8396 & 0.0001 & 0.0001 & 6.0120 & 0.0000 & 5.0708 & 0.0000 & 0.0001 \\
\hline Isle of Wight & 0.1268 & 0.8991 & -0.1691 & 0.8657 & 0.4246 & 0.5679 & 0.5701 & -0.3751 & 0.7076 & 0.2148 \\
\hline Medway & 6.1721 & 0.0000 & -2.9074 & 0.0036 & 0.0001 & 6.6653 & 0.0000 & -1.0532 & 0.2922 & 0.0001 \\
\hline Kent CC & 5.2560 & 0.0000 & 1.4774 & 0.1396 & 0.0001 & 5.9797 & 0.0000 & 1.3738 & 0.1695 & 0.0001 \\
\hline \multicolumn{11}{|l|}{ SOUTH WEST } \\
\hline Bristol, City of & 1.7671 & 0.0772 & 0.8981 & 0.3691 & 0.0400 & 0.7132 & 0.4757 & 0.3466 & 0.7289 & 0.2208 \\
\hline $\begin{array}{l}\text { North and North East Somerset, } \\
\text { South Gloucestershire }\end{array}$ & 0.9128 & 0.3613 & 1.1927 & 0.2330 & 0.2008 & 0.4723 & 0.6367 & 0.2567 & 0.7974 & 0.3077 \\
\hline Gloucestershire & -0.0406 & 0.9676 & -0.0012 & 0.9991 & 0.4725 & 0.0222 & 0.9822 & 0.0549 & 0.9562 & 0.4895 \\
\hline Swindon & 4.4627 & 0.0000 & 5.0513 & 0.0000 & 0.0001 & 5.2742 & 0.0000 & 4.3853 & 0.0000 & 0.0001 \\
\hline Wiltshire CC & 2.4036 & 0.0162 & 0.9761 & 0.3290 & 0.0130 & 1.9537 & 0.0507 & -0.3465 & 0.7290 & 0.0290 \\
\hline Bournemouth and Poole & 0.8573 & 0.3913 & 0.0721 & 0.9425 & 0.1988 & 0.9697 & 0.3322 & 0.0671 & 0.9465 & 0.1618 \\
\hline Dorset CC & 0.7111 & 0.4770 & -0.1497 & 0.8810 & 0.2338 & 0.2406 & 0.8098 & -0.1087 & 0.9135 & 0.3427 \\
\hline Somerset & 1.1018 & 0.2706 & -0.1380 & 0.8902 & 0.1608 & -0.5052 & 0.6134 & 0.4238 & 0.6717 & 0.3027 \\
\hline Cornwall and Isles of Scilly & 0.0029 & 0.9977 & -0.0150 & 0.9881 & 0.4456 & -1.0298 & 0.3031 & 1.3713 & 0.1703 & 0.0839 \\
\hline Plymouth & -0.4501 & 0.6526 & -0.0186 & 0.9852 & 0.3247 & -1.9894 & 0.0467 & 1.9823 & 0.0474 & 0.0040 \\
\hline Torbay & 0.1894 & 0.8498 & 0.1414 & 0.8875 & 0.4166 & -0.9291 & 0.3528 & 1.2461 & 0.2127 & 0.1429 \\
\hline Devon CC & -0.1301 & 0.8964 & 0.0262 & 0.9791 & 0.4466 & -1.7700 & 0.0767 & 0.8670 & 0.3860 & 0.0601 \\
\hline
\end{tabular}


TABLE A2: Local Spatial Correlation Statistics

\begin{tabular}{|c|c|c|c|c|c|c|c|c|c|c|}
\hline \multirow[b]{3}{*}{ NUTS3 area } & \multicolumn{5}{|c|}{ GVA per (employee) hour worked } & \multicolumn{5}{|c|}{ Average hourly earnings } \\
\hline & \multicolumn{2}{|c|}{ Getis Ord } & \multicolumn{2}{|c|}{ Local Moran's I } & \multirow[b]{2}{*}{ p2 } & \multicolumn{2}{|c|}{ Getis Ord } & \multicolumn{2}{|c|}{ Local Moran I } & \multirow[b]{2}{*}{$p 2$} \\
\hline & $G_{i}$ & $p 1$ & $z\left(I_{i}\right)$ & $p 1$ & & $\boldsymbol{G}_{i}$ & p1 & $z\left(\boldsymbol{I}_{i}\right)$ & $p 1$ & \\
\hline \multicolumn{11}{|l|}{ WALES } \\
\hline Gwynedd+Anglesey & 0.1194 & 0.9050 & -0.0396 & 0.9684 & 0.4406 & -0.6745 & 0.5000 & 0.4225 & 0.6727 & 0.2168 \\
\hline Conwy and Denbeighshire & -2.1689 & 0.0301 & 1.0819 & 0.2793 & 0.0110 & -0.6093 & 0.5423 & 0.4113 & 0.6808 & 0.2897 \\
\hline South West Wales & -0.2931 & 0.7695 & -0.1769 & 0.8596 & 0.3896 & -0.9763 & 0.3289 & 0.7547 & 0.4504 & 0.1538 \\
\hline Central Valleys & 0.4876 & 0.6259 & -0.2187 & 0.8269 & 0.3247 & -0.5898 & 0.5553 & 0.6091 & 0.5425 & 0.2637 \\
\hline Gwent Valleys & 0.5120 & 0.6086 & -0.2825 & 0.7776 & 0.3127 & -0.6326 & 0.5270 & 0.5525 & 0.5806 & 0.2737 \\
\hline Bridgend and Neath Port Talbot & 0.2895 & 0.7722 & 0.1094 & 0.9129 & 0.3766 & -0.7217 & 0.4705 & 0.3800 & 0.7039 & 0.2527 \\
\hline Swansea & -0.0431 & 0.9657 & 0.0376 & 0.9700 & 0.4905 & -0.8587 & 0.3905 & 0.2708 & 0.7865 & 0.1758 \\
\hline Monmouthshire and Newport & 1.3349 & 0.1819 & -0.8973 & 0.3696 & 0.1029 & 0.6919 & 0.4890 & -0.0540 & 0.9569 & 0.2488 \\
\hline Cardiff and Vale of Glamaorgan & 0.8101 & 0.4179 & 0.2645 & 0.7914 & 0.2328 & -0.1652 & 0.8688 & -0.0571 & 0.9545 & 0.4535 \\
\hline Flintshire and Wrexham & -3.7802 & 0.0002 & -2.4876 & 0.0129 & 0.0001 & -1.2089 & 0.2267 & 0.4652 & 0.6418 & 0.1039 \\
\hline Powys & -0.3595 & 0.7192 & -0.0979 & 0.9220 & 0.3746 & -1.1541 & 0.2484 & 1.0736 & 0.2830 & 0.0539 \\
\hline \multicolumn{11}{|l|}{ SCOTLAND } \\
\hline $\begin{array}{l}\text { Aberdeen City, Aberdeenshire } \\
\text { and North East Moray }\end{array}$ & -0.1501 & 0.8807 & -0.2206 & 0.8254 & 0.4735 & -0.5909 & 0.5546 & -0.2980 & 0.7657 & 0.2617 \\
\hline Angus and Dundee City & 0.5564 & 0.5779 & -0.0668 & 0.9467 & 0.2957 & -0.4891 & 0.6248 & 0.3258 & 0.7446 & 0.3566 \\
\hline Clackmannanshire and Fife & -0.2863 & 0.7747 & 0.3418 & 0.7325 & 0.3606 & -1.0936 & 0.2741 & 0.6017 & 0.5474 & 0.0939 \\
\hline East Lothian and Midlothian & -0.7398 & 0.4594 & -0.3548 & 0.7227 & 0.2318 & -1.0206 & 0.3074 & 0.8588 & 0.3905 & 0.1479 \\
\hline Scottish Borders, The & -0.2589 & 0.7957 & 0.3662 & 0.7142 & 0.3926 & -0.7209 & 0.4710 & 0.9835 & 0.3254 & 0.2408 \\
\hline Edinburgh, City of & -0.9112 & 0.3622 & -1.0676 & 0.2857 & 0.1528 & -1.5221 & 0.1280 & -1.8096 & 0.0704 & 0.0513 \\
\hline Falkirk & -0.7125 & 0.4762 & -0.2627 & 0.7927 & 0.2468 & -1.1833 & 0.2367 & 0.2198 & 0.8260 & 0.1019 \\
\hline Perth and Kinross and Stirling & -0.0928 & 0.9261 & 0.0867 & 0.9309 & 0.4585 & -0.4739 & 0.6356 & 0.2849 & 0.7757 & 0.3636 \\
\hline West Lothian & -0.7405 & 0.4590 & -0.9818 & 0.3262 & 0.2428 & -1.1038 & 0.2697 & 0.5241 & 0.6002 & 0.1219 \\
\hline $\begin{array}{l}\text { East and West Dunbartonshire, } \\
\text { Helensburgh and Lomond }\end{array}$ & 0.1467 & 0.8833 & -0.0117 & 0.9907 & 0.4366 & -0.8266 & 0.4085 & -0.3380 & 0.7354 & 0.1978 \\
\hline Dumfries and Galloway & 0.4678 & 0.6399 & -0.6478 & 0.5171 & 0.3127 & -0.6493 & 0.5161 & 0.5368 & 0.5914 & 0.2607 \\
\hline $\begin{array}{l}\text { East Ayrshire and North Ayrshire } \\
\text { Mainland }\end{array}$ & -0.2237 & 0.8230 & -0.0910 & 0.9275 & 0.3906 & -0.5493 & 0.5828 & 0.5186 & 0.6041 & 0.3247 \\
\hline Glasgow City & -0.2227 & 0.8238 & 0.1591 & 0.8736 & 0.3966 & -1.1249 & 0.2606 & -0.1981 & 0.8430 & 0.0959 \\
\hline $\begin{array}{l}\text { Inverclyde, East Renfrewshire } \\
\text { and Renfrewshire }\end{array}$ & 0.0310 & 0.9753 & 0.0353 & 0.9719 & 0.4775 & -0.6898 & 0.4903 & 0.0938 & 0.9253 & 0.2428 \\
\hline North Lanarkshire & -0.1333 & 0.8939 & 0.1430 & 0.8863 & 0.4436 & -1.0777 & 0.2812 & 0.6300 & 0.5287 & 0.1299 \\
\hline South Ayrshire & -0.6068 & 0.5440 & -0.3618 & 0.7175 & 0.2867 & -0.8034 & 0.4217 & 0.1031 & 0.9179 & 0.2218 \\
\hline South Lanarkshire & -0.6801 & 0.4965 & 0.2263 & 0.8210 & 0.2557 & -1.2271 & 0.2198 & 0.1945 & 0.8458 & 0.0849 \\
\hline Highlands & -1.6165 & 0.1068 & 0.1034 & 0.9176 & 0.2150 & -0.8587 & 0.3905 & 0.1544 & 0.8774 & 0.1270 \\
\hline
\end{tabular}

* p-values significant at the 0.05 level and using the Bonferroni correction (i.e. 0.00043 ) are marked in bold and bold-italics respectively

Deleted: đI
TABLE A4 Robustness analysis for local indicators of spatial associ: $\ldots$... [3] 
TABLE A3; Local Spatial Correlation Statistics*

\begin{tabular}{|c|c|c|c|c|c|c|c|c|c|c|}
\hline \multirow[b]{3}{*}{ NUTS3 area } & \multicolumn{5}{|c|}{ Index of occupational composition } & \multicolumn{5}{|c|}{ Index of productivity } \\
\hline & \multicolumn{2}{|c|}{ Getis Ord } & \multicolumn{3}{|c|}{ Local Moran's I } & \multicolumn{2}{|c|}{ Getis Ord } & \multicolumn{3}{|c|}{ Local Moran I } \\
\hline & $\boldsymbol{G}_{\boldsymbol{i}}$ & $p 1$ & $z\left(I_{i}\right)$ & $p 1$ & $p 2$ & $\boldsymbol{G}_{i}$ & p1 & $z\left(I_{i}\right)$ & $p 1$ & p2 \\
\hline \multicolumn{11}{|l|}{ NORTH EAST } \\
\hline Hartlepool and Stockton-on-Tees & -2.2050 & 0.0275 & 1.1967 & 0.2314 & 0.0609 & -1.3192 & 0.1871 & 0.7236 & 0.4693 & 0.0789 \\
\hline South Teesside & -1.4147 & 0.1572 & 1.5244 & 0.1274 & 0.0639 & -1.1182 & 0.2635 & 0.0760 & 0.9394 & 0.1039 \\
\hline Darlington & -2.1685 & 0.0301 & 0.7376 & 0.4607 & 0.0290 & -1.2807 & 0.2003 & 1.4552 & 0.1456 & 0.0859 \\
\hline Durham CC & -1.7030 & 0.0886 & 1.1797 & 0.2381 & 0.0449 & -1.3421 & 0.1796 & 1.0281 & 0.3039 & 0.0539 \\
\hline Northumberland & -2.0517 & 0.0402 & 0.6433 & 0.5200 & 0.0360 & -1.9894 & 0.0467 & 2.4001 & 0.0164 & 0.0080 \\
\hline Tyneside & -1.5845 & 0.1131 & 0.6014 & 0.5476 & 0.0460 & -1.8116 & 0.0700 & 0.3691 & 0.7121 & 0.0160 \\
\hline Sunderland & -1.1273 & 0.2596 & 1.5323 & 0.1255 & 0.1329 & -1.2459 & 0.2128 & 0.8357 & 0.4033 & 0.1129 \\
\hline \multicolumn{11}{|l|}{ NORTH WEST } \\
\hline Cumbria & -2.2323 & 0.0256 & 0.9193 & 0.3579 & 0.0729 & -1.2001 & 0.2301 & 0.7023 & 0.4825 & 0.0849 \\
\hline Halton and Warrington & -1.2596 & 0.2078 & -0.0706 & 0.9438 & 0.0939 & -0.6542 & 0.5130 & 0.0256 & 0.9796 & 0.2537 \\
\hline Cheshire CC & -2.1918 & 0.0284 & -1.8517 & 0.0641 & 0.0419 & -0.5368 & 0.5914 & -0.3096 & 0.7569 & 0.2747 \\
\hline Greater Manchester South & -2.0169 & 0.0437 & -0.3741 & 0.7083 & 0.0200 & -1.3628 & 0.1729 & -1.2033 & 0.2289 & 0.0799 \\
\hline Greater Manchester North & -2.3062 & 0.0211 & 0.5240 & 0.6003 & 0.0060 & -1.9743 & 0.0483 & 0.9105 & 0.3626 & 0.0510 \\
\hline Blackburn wi & -2.0660 & 0.0388 & 1.7788 & 0.0753 & 0.0360 & -1.4018 & 0.1610 & 0.9960 & 0.3193 & 0.0609 \\
\hline Blackpool & -1.4617 & 0.1438 & 0.8896 & 0.3737 & 0.0639 & -0.5744 & 0.5657 & 0.5472 & 0.5843 & 0.3157 \\
\hline Lancashire CC & -1.4482 & 0.1476 & -0.5559 & 0.5783 & 0.0699 & -0.6531 & 0.5137 & 0.0755 & 0.9398 & 0.2418 \\
\hline East Merseyside & -1.3242 & 0.1854 & 1.3640 & 0.1726 & 0.0879 & -0.9834 & 0.3254 & -0.8836 & 0.3769 & 0.1588 \\
\hline Liverpo & -1.3293 & 0.1837 & -0.1250 & 0.9005 & 0.0979 & -0.9394 & 0.3475 & -0.0064 & 0.9949 & 0.1868 \\
\hline Sefton & -1.3544 & 0.1756 & -0.2613 & 0.7938 & 0.0819 & -0.7797 & 0.4356 & 0.4403 & 0.6598 & 0.1928 \\
\hline Wirral & -1.1874 & 0.2351 & -0.2501 & 0.8025 & 0.1069 & -0.8286 & 0.4073 & 0.2315 & 0.8170 & 0.2058 \\
\hline \multicolumn{11}{|c|}{ YORKSHIRE AND HUMBERSIDE } \\
\hline Kingston upon Hull, City of & -0.9598 & 0.3372 & 1.8207 & 0.0686 & 0.1409 & -1.0857 & 0.2776 & 1.0974 & 0.2725 & 0.1169 \\
\hline East Riding of $\mathrm{Yo}$ & -1.4735 & 0.1406 & -0.3910 & 0.6958 & 0.0629 & -1.1595 & 0.2463 & 0.7989 & 0.4243 & 0.0959 \\
\hline North and N E Lincolnshire & -1.5953 & 0.1107 & 1.7237 & 0.0848 & 0.0529 & -1.4224 & 0.1549 & 1.2034 & 0.2288 & 0.0669 \\
\hline York & -2.4084 & 0.0160 & -0.3603 & 0.7187 & 0.0060 & -1.5732 & 0.1157 & -0.5024 & 0.6154 & 0.0430 \\
\hline North Yorkshire CC & -2.6185 & 0.0088 & -1.6884 & 0.0913 & 0.0020 & -1.6331 & 0.1025 & 0.7734 & 0.4393 & 0.0610 \\
\hline Barnsley, Doncaster, Rotherham & -1.8575 & 0.0632 & 2.9896 & 0.0028 & 0.0250 & -0.4988 & 0.6179 & 0.5075 & 0.6118 & 0.3307 \\
\hline Sheffield & -1.5622 & 0.1182 & -0.6498 & 0.5158 & 0.0539 & -0.4567 & 0.6479 & 0.1405 & 0.8882 & 0.3297 \\
\hline Bradford & -1.9894 & 0.0467 & 1.3223 & 0.1861 & 0.0180 & -1.5413 & 0.1233 & 0.6114 & 0.5409 & 0.0460 \\
\hline Leeds & -2.3860 & 0.0170 & -0.0715 & 0.9430 & 0.0060 & -1.8994 & 0.0575 & -0.5788 & 0.5627 & 0.0160 \\
\hline Calderdale, Kirklees.Wakefield & -2.5650 & 0.0103 & 1.1666 & 0.2434 & 0.0040 & -1.8286 & 0.0675 & 0.2492 & 0.8032 & 0.0390 \\
\hline
\end{tabular}


TABLE A3; Local Spatial Correlation Statistics

\begin{tabular}{|c|c|c|c|c|c|c|c|c|c|c|}
\hline \multirow[b]{3}{*}{ NUTS3 area } & \multicolumn{5}{|c|}{ Index of occupational composition } & \multicolumn{5}{|c|}{ Index of productivity } \\
\hline & \multicolumn{2}{|c|}{ Getis Ord } & \multicolumn{3}{|c|}{ Local Moran's I } & \multicolumn{2}{|c|}{ Getis Ord } & \multicolumn{3}{|c|}{ Local Moran I } \\
\hline & $\boldsymbol{G}_{\boldsymbol{i}}$ & p1 & $z\left(I_{i}\right)$ & p1 & p2 & $\boldsymbol{G}_{\boldsymbol{i}}$ & p1 & $z\left(I_{i}\right)$ & p1 & p2 \\
\hline \multicolumn{11}{|l|}{ EAST MIDLANDS } \\
\hline Derby & -1.5419 & 0.1231 & 0.1699 & 0.8651 & 0.0689 & -0.0455 & 0.9637 & -0.0007 & 0.9995 & 0.4985 \\
\hline Derbyshire & -1.8263 & 0.0678 & -0.3307 & 0.7409 & 0.0660 & -0.2420 & 0.8088 & 0.1901 & 0.8492 & 0.4066 \\
\hline Nottingham & -1.3648 & 0.1723 & 0.8362 & 0.4030 & 0.0769 & -0.3513 & 0.7254 & 0.1177 & 0.9063 & 0.3497 \\
\hline Nottinghamshire & -1.5455 & 0.1222 & -0.6118 & 0.5407 & 0.1070 & -0.6843 & 0.4938 & 0.3271 & 0.7436 & 0.2677 \\
\hline Leicester & 1.1403 & 0.2542 & -1.7494 & 0.0802 & 0.1369 & -1.9537 & 0.0507 & -1.3778 & 0.1683 & 0.0170 \\
\hline Leicestershire CC and Rutland & -1.2356 & 0.2166 & -0.5337 & 0.5936 & 0.1009 & 0.1270 & 0.8989 & 0.0198 & 0.9842 & 0.4486 \\
\hline Northamptonshire & 2.7308 & 0.0063 & -0.6532 & 0.5136 & 0.0050 & 4.7808 & 0.0000 & 1.6028 & 0.1090 & 0.0001 \\
\hline Lincolnshire & -1.6743 & 0.0941 & 0.2180 & 0.2232 & 0.1270 & -1.3893 & 0.1648 & 1.3479 & 0.1777 & 0.0539 \\
\hline \multicolumn{11}{|l|}{ WEST MIDLANDS } \\
\hline Herefordshire, County of & -0.4022 & 0.6875 & 0.0065 & 0.9948 & 0.3556 & -0.4626 & 0.6437 & 0.5102 & 0.6099 & 0.3546 \\
\hline Worcestershire & 0.8643 & 0.3874 & 0.0488 & 0.9610 & 0.2048 & 1.5230 & 0.1277 & -0.8357 & 0.4033 & 0.0779 \\
\hline Warwickshire & 2.7001 & 0.0069 & 0.7147 & 0.4748 & 0.0060 & 3.2376 & 0.0012 & 2.9413 & 0.0033 & 0.0020 \\
\hline Telford and Wrekin & -1.1818 & 0.2373 & 1.0948 & 0.2736 & 0.1049 & 0.3438 & 0.7310 & -0.2236 & 0.8231 & 0.3796 \\
\hline Shropshire CC & -1.0143 & 0.3104 & -0.1366 & 0.8913 & 0.1379 & -0.4406 & 0.6595 & 0.2665 & 0.7898 & 0.3337 \\
\hline Stoke-on-Trent & -1.0608 & 0.2888 & 2.1313 & 0.0331 & 0.1379 & -0.4379 & 0.6615 & 0.4704 & 0.6381 & 0.3267 \\
\hline Staffordshire CC & -1.0218 & 0.3069 & 0.2748 & 0.7835 & 0.1518 & 0.3866 & 0.6990 & -0.0645 & 0.9486 & 0.3397 \\
\hline Birmingham & 1.2465 & 0.2126 & 0.4596 & 0.6458 & 0.1189 & 2.3753 & 0.0175 & 2.0807 & 0.0375 & 0.0070 \\
\hline Solihull & 2.2865 & 0.0222 & 2.6683 & 0.0076 & 0.0170 & 3.1173 & 0.0018 & 3.6500 & 0.0003 & 0.0020 \\
\hline Coventry & 2.0704 & 0.0384 & -0.5800 & 0.5619 & 0.0190 & 3.1310 & 0.0017 & 2.7779 & 0.0055 & 0.0001 \\
\hline Dudley and Sandwell & 0.6685 & 0.5038 & -0.7847 & 0.4326 & 0.2817 & 1.1606 & 0.2458 & -0.4305 & 0.6668 & 0.1309 \\
\hline Walsall and Wolverhampton & -0.4272 & 0.6692 & 0.4358 & 0.6630 & 0.3217 & 0.4907 & 0.6236 & -0.1862 & 0.8523 & 0.3237 \\
\hline \multicolumn{11}{|l|}{ EAST } \\
\hline Peterborough & 0.8739 & 0.3822 & -0.3225 & 0.7471 & 0.1858 & 2.1306 & 0.0331 & 1.0161 & 0.3096 & 0.0340 \\
\hline Cambridgeshire CC & 2.9293 & 0.0034 & 4.5192 & 0.0000 & 0.0001 & 4.7525 & 0.0000 & 3.3811 & 0.0007 & 0.0001 \\
\hline Norfolk & -0.6295 & 0.5290 & 0.4782 & 0.6325 & 0.2837 & -0.1002 & 0.9202 & 0.0276 & 0.9780 & 0.4905 \\
\hline Suffolk & 1.5496 & 0.1212 & -0.7244 & 0.4688 & 0.0679 & 1.7938 & 0.0728 & -1.0708 & 0.2843 & 0.0569 \\
\hline Luton & 4.4418 & 0.0000 & -2.8115 & 0.0049 & 0.0001 & 6.3164 & 0.0000 & 6.5026 & 0.0000 & 0.0001 \\
\hline Bedfordshire CC & 3.7853 & 0.0002 & 4.7698 & 0.0000 & 0.0001 & 5.9831 & 0.0000 & 1.9315 & 0.0534 & 0.0001 \\
\hline Hertfordshire & 4.7446 & 0.0000 & 7.2415 & 0.0000 & 0.0001 & 6.6413 & 0.0000 & 11.3000 & 0.0000 & 0.0001 \\
\hline Southend-on-Sea & 4.5971 & 0.0000 & 3.1662 & 0.0015 & 0.0001 & 6.1557 & 0.0000 & -1.9331 & 0.0532 & 0.0001 \\
\hline Thurrock & 5.7415 & 0.0000 & -2.6552 & 0.0079 & 0.0001 & 6.1337 & 0.0000 & 6.9859 & 0.0000 & 0.0001 \\
\hline Essex CC & 5.5477 & 0.0000 & 4.5184 & 0.0000 & 0.0001 & 6.2073 & 0.0000 & 3.4913 & 0.0005 & 0.0001 \\
\hline
\end{tabular}


TABLE A3; Local Spatial Correlation Statistics

\begin{tabular}{|c|c|c|c|c|c|c|c|c|c|c|}
\hline \multirow[b]{3}{*}{ NUTS3 area } & \multicolumn{5}{|c|}{ Index of occupational composition } & \multicolumn{5}{|c|}{ Index of productivity } \\
\hline & \multicolumn{2}{|c|}{ Getis Ord } & \multicolumn{2}{|c|}{ Local Moran's I } & \multirow[b]{2}{*}{ p2 } & \multicolumn{2}{|c|}{ Getis Ord } & \multicolumn{2}{|c|}{ Local Moran I } & \multirow[b]{2}{*}{$p 2$} \\
\hline & $\boldsymbol{G}_{\boldsymbol{i}}$ & $p 1$ & $z\left(I_{i}\right)$ & p1 & & $G_{i}$ & p1 & $z\left(I_{i}\right)$ & p1 & \\
\hline \multicolumn{11}{|l|}{ LONDON } \\
\hline Inner London - West & 5.2173 & 0.0000 & 18.7455 & 0.0000 & 0.0001 & 6.9654 & 0.0000 & 30.5316 & 0.0000 & 0.0001 \\
\hline Inner London - East & 5.5848 & 0.0000 & 9.6419 & 0.0000 & 0.0001 & 6.4575 & 0.0000 & 24.6873 & 0.0000 & 0.0001 \\
\hline Outer London - East and NE & 5.6047 & 0.0000 & 1.8524 & 0.0640 & 0.0001 & 6.1560 & 0.0000 & 5.8580 & 0.0000 & 0.0001 \\
\hline Outer London - South & 5.4375 & 0.0000 & 9.8340 & 0.0000 & 0.0001 & 6.4803 & 0.0000 & 7.6446 & 0.0000 & 0.0001 \\
\hline Outer London - West and NW & 4.9846 & 0.0000 & 9.8692 & 0.0000 & 0.0001 & 6.2960 & 0.0000 & 14.7916 & 0.0000 & 0.0001 \\
\hline \multicolumn{11}{|l|}{ SOUTH EAST } \\
\hline Berkshire & 5.3728 & 0.0000 & 10.0769 & 0.0000 & 0.0001 & 6.4668 & 0.0000 & 13.7705 & 0.0000 & 0.0001 \\
\hline Milton Keynes & 3.2872 & 0.0010 & 2.2322 & 0.0256 & 0.0001 & 5.6296 & 0.0000 & 5.4760 & 0.0000 & 0.0001 \\
\hline Buckinghamshire CC & 4.7971 & 0.0000 & 11.4010 & 0.0000 & 0.0001 & 6.8222 & 0.0000 & 9.0613 & 0.0000 & 0.0001 \\
\hline Oxfordshire & 4.0513 & 0.0001 & 6.9510 & 0.0000 & 0.0001 & 6.1578 & 0.0000 & 5.5834 & 0.0000 & 0.0001 \\
\hline Brighton and Hove & 4.2569 & 0.0000 & 8.3410 & 0.0000 & 0.0001 & 6.3417 & 0.0000 & 0.9971 & 0.3187 & 0.0001 \\
\hline East Sussex CC & 4.3835 & 0.0000 & 2.5935 & 0.0095 & 0.0001 & 5.7659 & 0.0000 & -5.1966 & 0.0000 & 0.0001 \\
\hline Surrey & 5.2333 & 0.0000 & 12.7187 & 0.0000 & 0.0001 & 6.4801 & 0.0000 & 14.3239 & 0.0000 & 0.0001 \\
\hline West Sussex & 4.2219 & 0.0000 & 2.9546 & 0.0031 & 0.0001 & 5.7521 & 0.0000 & 4.2989 & 0.0000 & 0.0001 \\
\hline Portsmouth & 4.9755 & 0.0000 & -1.4820 & 0.1383 & 0.0001 & 5.7789 & 0.0000 & 3.1835 & 0.0015 & 0.0001 \\
\hline Southampton & 5.3196 & 0.0000 & -2.0910 & 0.0365 & 0.0001 & 6.2985 & 0.0000 & 5.4350 & 0.0000 & 0.0001 \\
\hline Hampshire CC & 5.1907 & 0.0000 & 4.1362 & 0.0000 & 0.0001 & 6.0403 & 0.0000 & 5.1297 & 0.0000 & 0.0001 \\
\hline Isle of Wight & -0.0061 & 0.9952 & 0.0088 & 0.9930 & 0.4765 & 1.2446 & 0.2133 & -0.6489 & 0.5164 & 0.0809 \\
\hline Medway & 6.3069 & 0.0000 & -6.5344 & 0.0000 & 0.0001 & 6.3442 & 0.0000 & 0.7841 & 0.4330 & 0.0001 \\
\hline Kent CC & 5.0127 & 0.0000 & 1.5889 & 0.1121 & 0.0001 & 5.9999 & 0.0000 & 2.6593 & 0.0078 & 0.0001 \\
\hline \multicolumn{11}{|l|}{ SOUTH WEST } \\
\hline Bristol, City of & 0.8920 & 0.3724 & 0.4408 & 0.6594 & 0.1818 & 0.4840 & 0.6284 & 0.2634 & 0.7922 & 0.3117 \\
\hline $\begin{array}{l}\text { North and North East Somerset, } \\
\text { South Gloucestershire }\end{array}$ & 0.9656 & 0.3342 & 0.7078 & 0.4791 & 0.1778 & 0.0331 & 0.9736 & 0.0465 & 0.9629 & 0.4695 \\
\hline Gloucestershire & -0.5201 & 0.6030 & -0.2964 & 0.7669 & 0.3007 & 0.1039 & 0.9172 & 0.0727 & 0.9420 & 0.4555 \\
\hline Swindon & 3.8639 & 0.0001 & 0.5517 & 0.5812 & 0.0001 & 5.1886 & 0.0000 & 5.7927 & 0.0000 & 0.0001 \\
\hline Wiltshire CC & 2.4285 & 0.0152 & 1.3972 & 0.1623 & 0.0070 & 2.0653 & 0.0389 & -1.2493 & 0.2116 & 0.0280 \\
\hline Bournemouth and Poole & 0.9734 & 0.3303 & -0.0450 & 0.9641 & 0.1638 & 1.2294 & 0.2189 & 0.3954 & 0.6925 & 0.1249 \\
\hline Dorset CC & 0.3497 & 0.7266 & 0.1040 & 0.9172 & 0.3377 & 0.5051 & 0.6135 & -0.4295 & 0.6675 & 0.2777 \\
\hline Somerset & -0.2177 & 0.8277 & 0.1178 & 0.9063 & 0.3856 & -0.9516 & 0.3413 & 0.8133 & 0.4161 & 0.1379 \\
\hline Cornwall and Isles of Scilly & -0.9689 & 0.3326 & 0.2759 & 0.7827 & 0.1319 & -0.9991 & 0.3177 & 1.6395 & 0.1011 & 0.1249 \\
\hline Plymouth & -0.4726 & 0.6365 & 0.7178 & 0.4729 & 0.3167 & -1.9537 & 0.0507 & 1.6171 & 0.1059 & 0.0020 \\
\hline Torbay & -0.6676 & 0.5044 & 0.2959 & 0.7673 & 0.2717 & -0.9131 & 0.3612 & 1.4442 & 0.1487 & 0.1618 \\
\hline Devon CC & -0.9861 & 0.3241 & -0.1755 & 0.8607 & 0.1698 & -1.9190 & 0.0550 & 1.4487 & 0.1474 & 0.0600 \\
\hline
\end{tabular}


TABLE A3: Local Spatial Correlation Statistics

\begin{tabular}{|c|c|c|c|c|c|c|c|c|c|c|}
\hline \multirow[b]{3}{*}{ NUTS3 area } & \multicolumn{5}{|c|}{ Index of occupational composition } & \multicolumn{5}{|c|}{ Index of productivity } \\
\hline & \multicolumn{2}{|c|}{ Getis Ord } & \multicolumn{2}{|c|}{ Local Moran's I } & \multirow[b]{2}{*}{$p 2$} & \multicolumn{2}{|c|}{ Getis Ord } & \multicolumn{2}{|c|}{ Local Moran I } & \multirow[b]{2}{*}{$p 2$} \\
\hline & $G_{i}$ & $p 1$ & $z\left(I_{i}\right)$ & $p 1$ & & $\boldsymbol{G}_{\boldsymbol{i}}$ & $p 1$ & $z\left(I_{i}\right)$ & p1 & \\
\hline \multicolumn{11}{|l|}{ WALES } \\
\hline Gwynedd+Anglesey & -0.3323 & 0.7397 & 0.2089 & 0.8345 & 0.3816 & -0.8338 & 0.4044 & 0.9510 & 0.3416 & 0.1738 \\
\hline Conwy and Denbeighshire & -1.1130 & 0.2657 & -0.4930 & 0.6220 & 0.1189 & -0.5475 & 0.5840 & 0.5762 & 0.5645 & 0.2987 \\
\hline South West Wales & -0.5607 & 0.5750 & 0.1798 & 0.8573 & 0.3027 & -1.4608 & 0.1441 & 1.5326 & 0.1254 & 0.0450 \\
\hline Central Valleys & 0.0908 & 0.9276 & -0.2234 & 0.8232 & 0.4785 & -1.1243 & 0.2609 & 0.9010 & 0.3676 & 0.1259 \\
\hline Gwent Valleys & 0.0328 & 0.9739 & -0.0919 & 0.9268 & 0.4715 & -1.0799 & 0.2802 & 1.0512 & 0.2932 & 0.1129 \\
\hline Bridgend and Neath Port Talbot & -0.1539 & 0.8777 & 0.1361 & 0.8917 & 0.4486 & -1.1266 & 0.2599 & 0.8930 & 0.3719 & 0.1229 \\
\hline Swansea & -0.8777 & 0.3801 & 0.1054 & 0.9161 & 0.1938 & -1.1567 & 0.2474 & 0.8506 & 0.3950 & 0.0949 \\
\hline Monmouthshire and Newport & 0.6259 & 0.5314 & 0.2870 & 0.7741 & 0.2667 & 0.4177 & 0.6762 & -0.0571 & 0.9545 & 0.3417 \\
\hline Cardiff and Vale of Glamaorgan & 0.0600 & 0.9521 & 0.0556 & 0.9556 & 0.4875 & -0.6472 & 0.5175 & -0.1759 & 0.8604 & 0.2517 \\
\hline Flintshire and Wrexham & -1.4165 & 0.1566 & 1.3214 & 0.1864 & 0.0739 & -1.2509 & 0.2110 & 0.2136 & 0.8309 & 0.0939 \\
\hline Powys & -0.0049 & 0.9961 & 0.0075 & 0.9940 & 0.4935 & -1.5502 & 0.1211 & 2.0811 & 0.0374 & 0.1180 \\
\hline \multicolumn{11}{|l|}{ SCOTLAND } \\
\hline $\begin{array}{l}\text { Aberdeen City, Aberdeenshire } \\
\text { and North East Moray }\end{array}$ & -0.9711 & 0.3315 & -0.3303 & 0.7412 & 0.1349 & -0.4449 & 0.6564 & -0.3166 & 0.7515 & 0.4106 \\
\hline Angus and Dundee City & -0.6373 & 0.5239 & 0.6330 & 0.5267 & 0.2647 & -0.2975 & 0.7661 & 0.1597 & 0.8731 & 0.4386 \\
\hline Clackmannanshire and Fife & -0.9162 & 0.3595 & 0.4618 & 0.6442 & 0.1608 & -0.7804 & 0.4351 & 0.4156 & 0.6777 & 0.1838 \\
\hline East Lothian and Midlothian & -0.8036 & 0.4216 & 0.7472 & 0.4549 & 0.2228 & -0.7250 & 0.4685 & 0.5413 & 0.5883 & 0.2418 \\
\hline Scottish Borders, The & -0.9893 & 0.3225 & 0.4459 & 0.6557 & 0.1588 & -0.5318 & 0.5949 & 0.7265 & 0.4675 & 0.3077 \\
\hline Edinburgh, City of & -1.5135 & 0.1302 & -2.7435 & 0.0061 & 0.0480 & -1.1127 & 0.2658 & -0.8953 & 0.3706 & 0.1139 \\
\hline Falkirk & -0.8882 & 0.3744 & 0.5435 & 0.5868 & 0.1818 & -0.9639 & 0.3351 & -0.1945 & 0.8458 & 0.1658 \\
\hline Perth and Kinross and Stirling & -0.7156 & 0.4743 & -0.1424 & 0.8868 & 0.2358 & -0.0821 & 0.9346 & 0.0776 & 0.9382 & 0.4845 \\
\hline West Lothian & -0.7571 & 0.4490 & 0.8786 & 0.3796 & 0.2438 & -0.8418 & 0.3999 & 0.0172 & 0.9863 & 0.2228 \\
\hline $\begin{array}{l}\text { East and West Dunbartonshire, } \\
\text { Helensburgh and Lomond }\end{array}$ & -0.9169 & 0.3592 & -0.7508 & 0.4528 & 0.1688 & -0.5143 & 0.6071 & -0.3111 & 0.7557 & 0.3067 \\
\hline Dumfries and Galloway & -0.8884 & 0.3743 & 0.8042 & 0.4213 & 0.2078 & -0.3611 & 0.7180 & 0.1620 & 0.8713 & 0.3706 \\
\hline $\begin{array}{l}\text { East Ayrshire and North Ayrshire } \\
\text { Mainland }\end{array}$ & -0.7448 & 0.4564 & 0.8021 & 0.4225 & 0.2328 & -0.0226 & 0.9820 & 0.0307 & 0.9755 & 0.4745 \\
\hline Glasgow City & -0.8108 & 0.4175 & -0.0297 & 0.9763 & 0.1968 & -0.8567 & 0.3916 & -0.3957 & 0.6923 & 0.1878 \\
\hline $\begin{array}{l}\text { Inverclyde, East Renfrewshire } \\
\text { and Renfrewshire }\end{array}$ & -0.7855 & 0.4322 & -0.2453 & 0.8062 & 0.2178 & -0.3061 & 0.7595 & 0.0765 & 0.9390 & 0.4016 \\
\hline North Lanarkshire & -0.8214 & 0.4114 & 0.7547 & 0.4504 & 0.2168 & -0.6957 & 0.4866 & 0.4344 & 0.6640 & 0.2418 \\
\hline South Ayrshire & -1.1230 & 0.2615 & 0.1789 & 0.8580 & 0.1349 & -0.2676 & 0.7890 & -0.0137 & 0.9891 & 0.4446 \\
\hline South Lanarkshire & -0.9424 & 0.3460 & 0.3187 & 0.7500 & 0.1828 & -0.8280 & 0.4077 & 0.0122 & 0.9902 & 0.1958 \\
\hline Highlands & -0.9181 & 0.3585 & 0.2384 & 0.8116 & 0.1621 & -0.8794 & 0.3792 & 0.0396 & 0.9684 & 0.3488 \\
\hline
\end{tabular}

* p-values significant at the 0.05 level and using the Bonferroni correction (i.e. 0.00043) are marked in bold and bold-italics respectively. 
Page 1: [1] Deleted

Eleonora Patacchini

2/22/2006 10:00:00 AM

\section{Appendix 1: Methods of Exploratory Spatial Data Analysis}

\section{Global spatial autocorrelation}

When the variable under investigation is measured on a continuous scale, the measurement of global spatial autocorrelation is usually based on Moran's $I$ and Geary's $c$ statistics (Cliff and Ord, 1981).

Moran's $I$ is defined as

$$
I=\frac{n}{S_{0}} \frac{\sum_{i} \sum_{j} w_{i j}\left(x_{i}-\bar{x}\right)\left(x_{j}-\bar{x}\right)}{\sum_{i}\left(x_{i}-\bar{x}\right)^{2}}
$$

(1)

where $n$ is the number of observations, $x_{i}$ denotes the observation at site $i$ for the variable of interest $X$, and $w_{i j}$ denotes the elements of the spatial weights matrix. $S_{0}$ is a scaling factor equal to the sum of all the elements in the weight matrix. The spatial weight matrix may be row-standardised such that the elements $\tilde{w}_{i j}$ in each row sum to 1 in order to normalise the size of the neighbourhood set for each site. In this case $S_{0}=\mathrm{n}$ and the expression (1) simplifies to a ratio of the spatial cross-product to the variance. Moran's $I$ is a cross product coefficient scaled to be less than one in value, with an expected value $E(I)=-1 /(n-1) \approx 0$ for $n$ sufficiently large. Values for Moran's $I$ larger (smaller) than the expected value indicate positive (negative) spatial correlation.

An alternative measure of global spatial autocorrelation is given by Geary's $c$ coefficient which is based on squared deviations. Geary's $c$ is defined as

$$
c=\frac{(n-1)}{2 S_{0}} \frac{\sum_{i} \sum_{j} w_{i j}\left(x_{i}-x_{j}\right)^{2}}{\sum_{i}\left(x_{i}-\bar{x}\right)^{2}}
$$

The expected value for Geary's $\mathrm{c}$ is 1 . Values of Geary's $c$ less than one indicate positive spatial correlation, while values larger than one suggest negative spatial correlation. 
Inference is typically based on a standardised z-value of the statistic computed by subtracting the expected value and dividing by the standard deviation in the usual way. Assuming that the variable of interest is normally distributed, the z-value follows a standard normal distribution, and the significance of the test statistic may be judged by comparing the computed $\mathrm{z}$-value with its probability in the standard normal tables (for a theoretical discussion and detailed expressions for the moments of the (asymptotic) distributions of $I$ and $c$ under various assumptions, see Cliff and Ord (1981).). An alternative approach, referred to as the conditional randomization approach, is to assume that each value observed could equally likely have occurred at all locations. A reference distribution for the Moran's $I$ or the Geary c statistic is then generated empirically by randomly reshuffling the observed values over all possible locations and by re-computing the statistic for each new sample. A pseudo significance level is obtained as $p=\frac{T+1}{M+1}$ where $T$ is the number of the computed values of the test statistic that are equal to or larger than the observed value and $M$ is the number of permutations. Note that the highest level of significance (i.e. that corresponding to $T=0$ ) is determined by the chosen number of replications, $M$. Given a certain number of permutations, a low value of this pseudosignificance level implies that the observed 'value of the statistic ( $I$ or $c$ ) is extreme with respect to its reference distribution, and therefore the null hypothesis of spatial randomness should be rejected. Because of the theoretical limitations in using a normality approximation, the permutation approach is also usually considered (see Anselin 1988 and 1995 for more details).

\section{Local spatial autocorrelation}

Both Moran's I and Geary's $c$ statistics are global statistics, in the sense that the overall pattern in the data is summarized in a single statistic, and as such they may be of limited interest. Such global statistics may summarise a number of possible disparate spatial relationships for a given set of data. A number of local indicators of spatial association that measure spatial dependence in a region of the study area have been developed (Anselin, 1995a; Getis and Ord, 1995). These statistics detect significant associations between a single $x_{i}$ and its neighbours and are suited to the task of identifying clusters of 
high or low values of the variable or the existence of atypical localizations (spatial outliers) in the form of sites of high (low) values surrounded by areas of relatively low (high) values for the variable of interest.

\section{The Moran Scatterplot and the Local Moran's $I_{i}$}

A simple visual depiction of the relationship between the value of $X$ at site $i$ and the average of its neighbours is obtained by plotting $\left(x_{i}-\bar{x}\right)$ on the horizontal axis against its spatial lag $\sum_{j=1}^{n} \tilde{w}_{i j}\left(x_{j}-\bar{x}\right)$ on the vertical axis, where $\tilde{w}_{i j}$ denotes the elements of the (row-standardised) spatial weights matrix (i.e. the Moran Scatterplot).

The Moran's I measure of global spatial autocorrelation is formally equivalent to the estimate of the slope coefficient of the linear regression of $W z$ on $z$ where $W$ denotes the (row-standardized) weight matrix and $z$ denotes the vector of observations in deviation form i.e. $\left(x_{i}-\bar{x}\right)$. Using a row-standardized weight matrix (which implies $\mathrm{S} 0=\mathrm{n})$, Moran's $I$ in matrix form reduces to $I=z^{\prime} W z / z^{\prime} z$ where $z$ denotes the vector of observations in deviations form, i.e. $\left(x_{i}-\bar{x}\right)$. Given this, standard regression diagnostics may be used to detect outliers and to identify individual areas that exert strong influence on the global Moran's I statistic. 'Studentized' or normed residuals (i.e. the absolute value of the ith residual divided by the square root of the residual sum of squares) and leverage measures based on the diagonal elements in the Hat or Projection Matrix may be used to detect outliers. The Hat or Projection matrix $H=X\left(X^{\prime} X\right)^{-1} X^{\prime}$ where $X$ is the $n x k$ matrix of observations on the $\mathrm{k}$ explanatory variables in the regression. The extent to which such observations are influential may be assessed using Cook's distance criterion di which measures the effect on the estimated slope coefficient of excluding the ith observation (see Anselin, 1996 and 1995b for more details).

The four different quadrants of the so-called Moran scatterplot correspond to the four types of local spatial association between a spatial unit and its neighbours: $\mathrm{HH}$, contains areas with a high value surrounded by areas with high values, LH, contains areas with a low value surrounded by areas with high values; LL consists of low value areas surrounded by other areas with low values; HL consists of areas with high values surrounded by low value areas. Quadrants HH and LL correspond to positive spatial 
autocorrelation indicating spatial clustering of similar values; while the quadrants HL and LH correspond to negative spatial autocorrelation with groupings of dissimilar areas. While the Moran scatterplot shows the spatial regime (position across quadrants) of each location, it does not give an indication on the statistical significance of these local spatial association schemes. The existence of any significant local spatial pattern is detected by the use of local spatial correlation statistics (LISA).

.The 'local' version of Moran's $I$ statistic for each spatial unit i is defined as

$$
I_{i}=\frac{\left(x_{i}-\bar{x}\right) \sum_{j} \tilde{w}_{i j}\left(x_{j}-\bar{x}\right)}{\sum_{i}\left(x_{i}-\bar{x}\right)^{2} / n}
$$

where $n$ is the number of observations, $x_{i}$ denotes the observation on unit $\mathrm{i}$ for the variable $X$ and $\tilde{w}_{i j}$ denotes the elements of the (row-standardised) spatial weights matrix as before. It follows that the global Moran $I$ is related to the local version as follows

$$
I=\sum_{i} I_{i}
$$

i.e. the sum of all local Moran values is proportional to the global Moran's statistic. The local Moran focuses on the correlation between the value of the variable $X$ at site $i$ and its neighbouring values. In the presence of global spatial autocorrelation, inference should be based on the conditional permutation approach described above (Anselin, 1995). A significant and positive value for $I_{i}$ indicates a local spatial clustering of similar values of the variable $X$, either high or low. If the local Moran's statistic, $I_{i}$, is significant and negative then the value of $X$ at site $i$ and those for its neighbours are dissimilar. To detect whether an area with a positive local statistic is in the HH or LL spatial regime and whether an area with a negative local statistic is in the HL or LH spatial regime, one has to look at its position in the Moran scatterplot, hence the complementarity between local Moran's statistics and Moran scatterplots.

\section{Getis Ord Statistics}

Alternative measures of local spatial correlation are the Getis Ord statistics (Getis and Ord, 1995), which are based on a comparison of the sum of values within the neighbourhood set with the corresponding global value. 
There are two forms of the statistic

$$
G_{i}^{*}=\frac{\sum_{j} w_{i j} x_{j}-\bar{x} S_{0}}{\sqrt{\left(\sum_{j}\left(x_{j}-\bar{x}\right)^{2} / n\right)} \sqrt{\left(n \sum_{j} w_{i j}^{2}-S_{0}^{2}\right) /(n-1)}}
$$

and

$$
G_{i}=\frac{\sum_{j \neq i} w_{i j} x_{j}-\bar{x} S_{-i}}{\sqrt{\left(\sum_{j \neq i}\left(x_{j}-\bar{x}_{-i}\right)^{2} / n-1\right)} \sqrt{\left((n-1) \sum_{j \neq i} w_{i j}^{2}-S_{-i}^{2}\right) /(n-2)}}
$$

where $\bar{x}$ and $\bar{x}_{-i}$ denotes the sample mean of $x$ with and without the $i$ th observation included respectively. Similarly $S_{0}$ and $S_{-i}$ denote the sum of the spatial weights with and without the $i$ th weight included. Under the null hypothesis of spatial randomness, the sum of values of $X$ among the neighbourhood set would not differ systematically from the sum of values for the sample as a whole. The $G^{*}{ }_{i}$ statistic includes site $i$ in the summations that are the basis of the comparison, while it is excluded in the case of the $G_{i}$ statistic. The spatial clustering of high values of $X$ results in positive values for the $G^{*}$ and $G_{i}$ statistics, and negative values for $G^{*}{ }_{i}$ and $G_{i}$ are indicative of a clustering of relatively low values for $X$. Inference can be based on the asymptotic approximation to the standard normal distribution as suggested by Getis and Ord (1995), although the presence of global spatial autocorrelation may affect the power of the test.

Page 2: [2] Deleted Eleonora Patacchini 3/10/2006 5:53:00 PM TABLE A1 : Moran Scatterplot - Tests for Outliers Spatial weight matrix: estimated travel time $\leq 90$ minutes Leverage Cook's NUTS3 area Measure* distance 


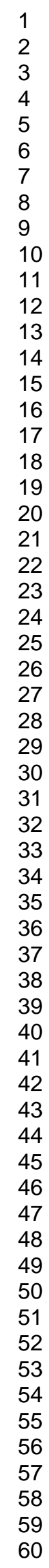 \\ Page 43 of 47} Regional Studies

1

2

4

5

7

8

10

11

(1)

14

15

16

18

19

20

22

23

25

26

27

29

30

32

33

34

36

37

38

39

40

41

42

44

45

46

47

48

50

51

52

54

55

57

58

59

60

http://mc.manuscriptcentral.com/cres Email: regional.studies@fm.ru.nl 


\section{Figure 1: Spatial Distribution of Income in Great Britain} Quintiles by NUTS3 Administrative Areas

GVA per hour worked $14.792-17.097$ $17.097-17.882$ $17.882-18.819$

$18.819-19.99$

$19.99-25.198$

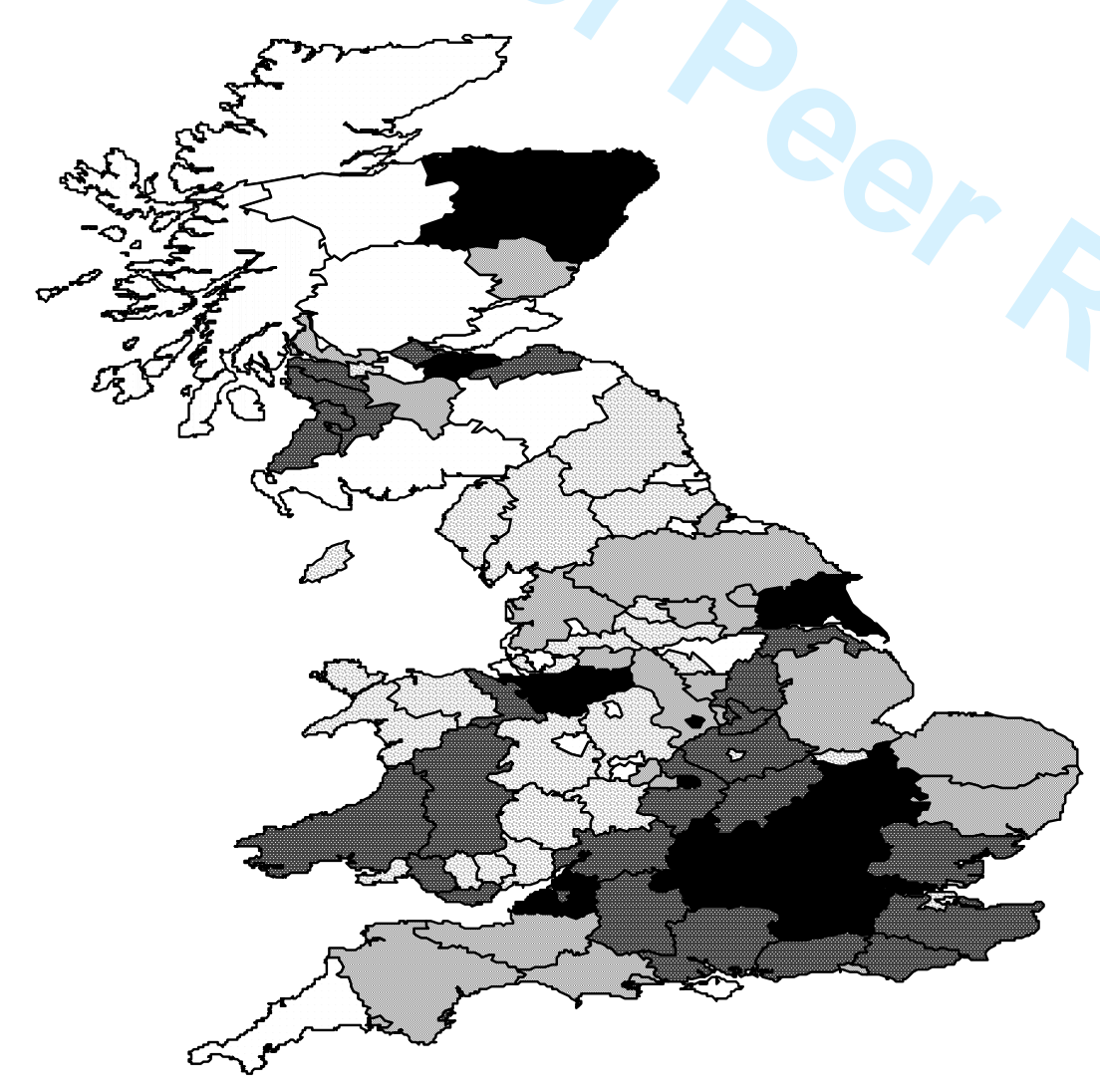

Average hourly earnings

\begin{tabular}{|l|l}
\hline & $7.988-8.894$ \\
\hline$\square$ & $8.894-9.235$ \\
9.235 & -9.708 \\
\hline \hline & $9.708-10.44$ \\
$10.44-17.547$
\end{tabular}


Spatial proximity lag: travel time of $<90 \mathrm{mins}$
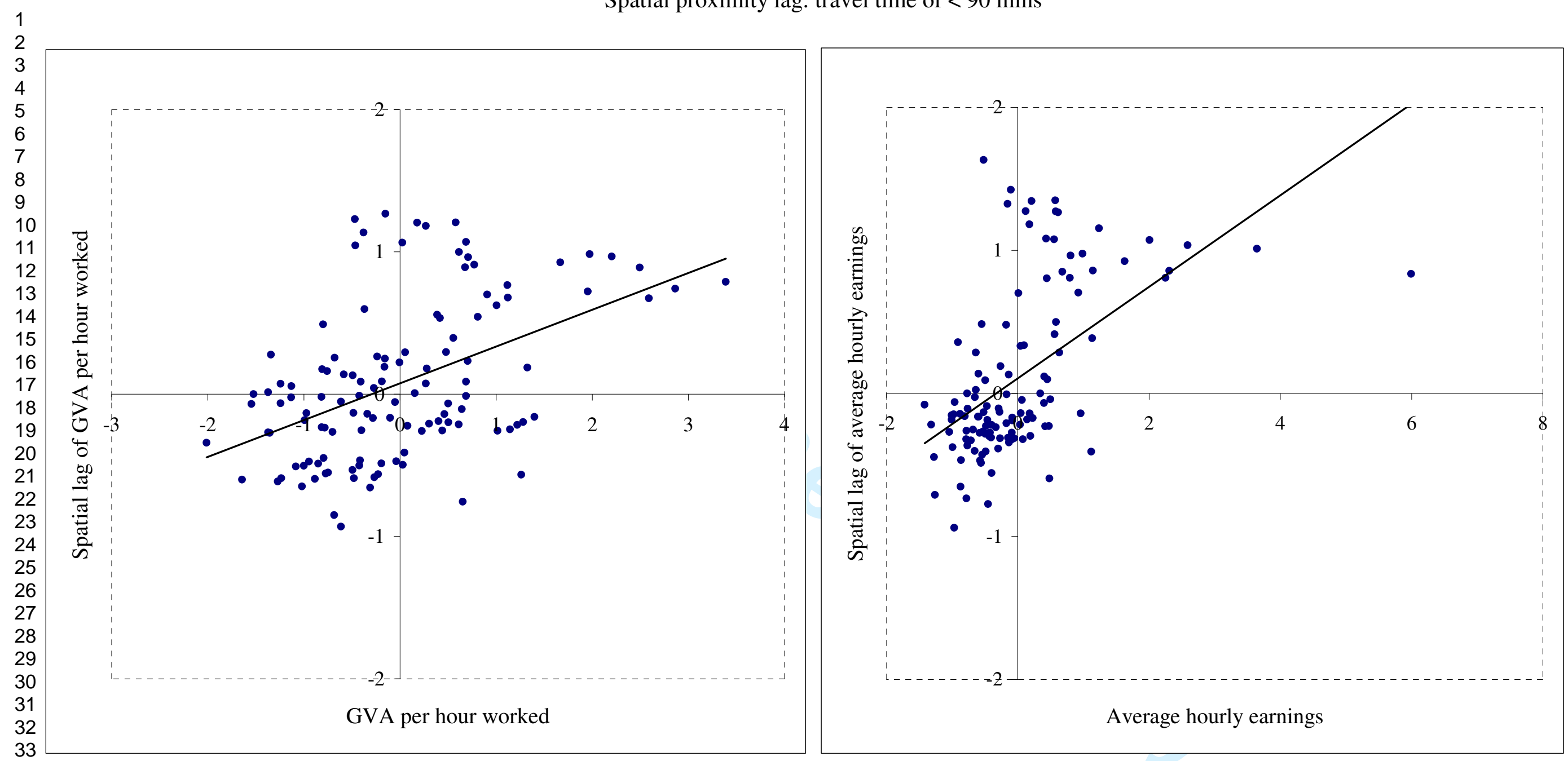

(Significant at 0.05 level)

GVA per hour worked

$$
\text { Not significant }
$$

$\mathrm{HH}$

LL

$\mathrm{HL}$

LH
Average hourly earnings

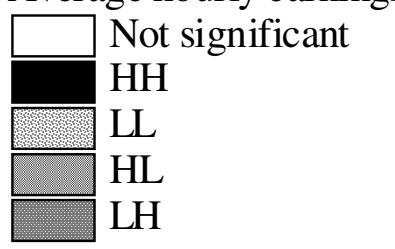
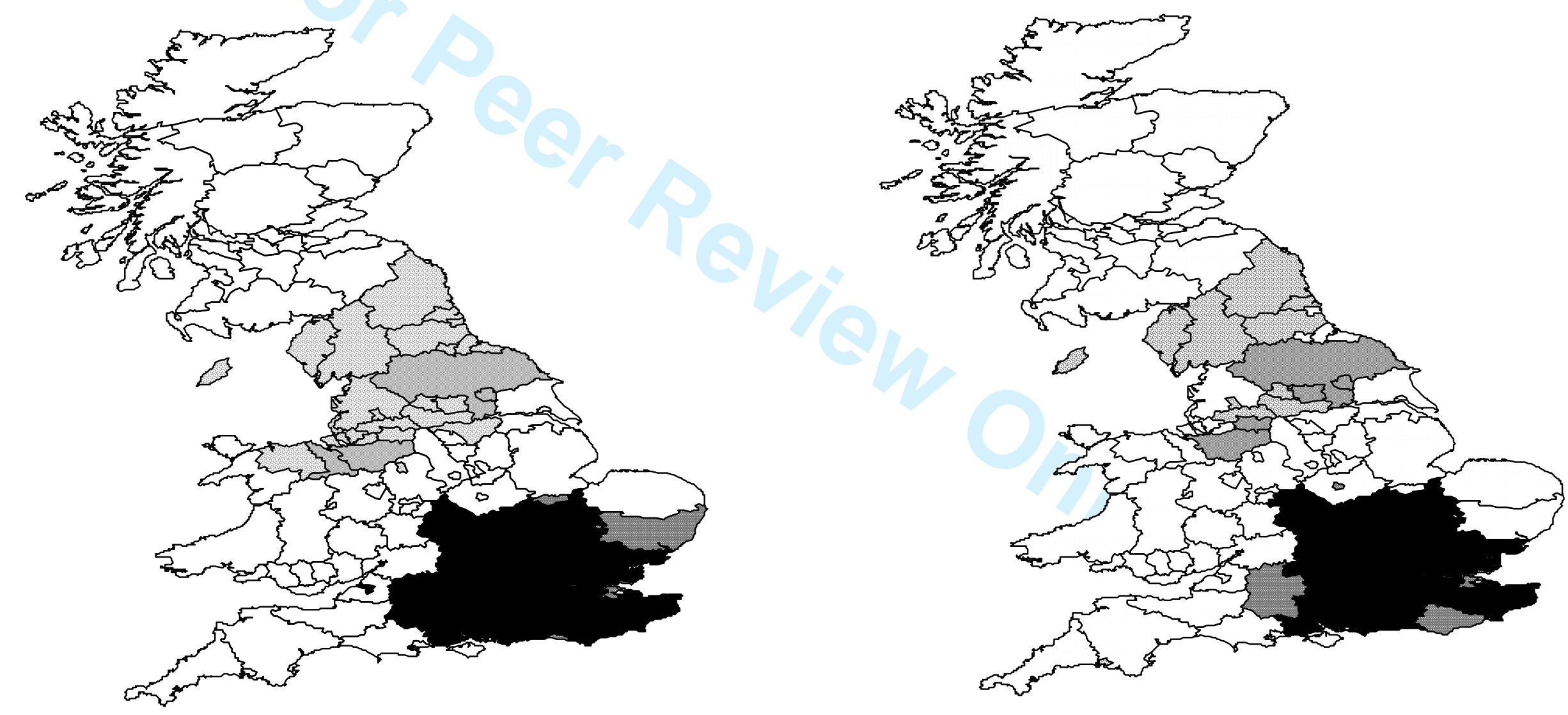
Figure 4: Local Indicators of Spatial Association for Occupational Composition and Productivity Indices (Significant at 0.05 level)

Occupational composition index

\begin{tabular}{|l|l}
\hline & Not \\
\hline \hline & $\mathrm{HH}$ \\
\hline \hline & $\mathrm{HL}$ \\
$\mathrm{LH}$ &
\end{tabular}
Productivity index

\begin{tabular}{|l}
\hline Not significant \\
HH \\
LL \\
\hline $\mathrm{HL}$ \\
LH
\end{tabular}
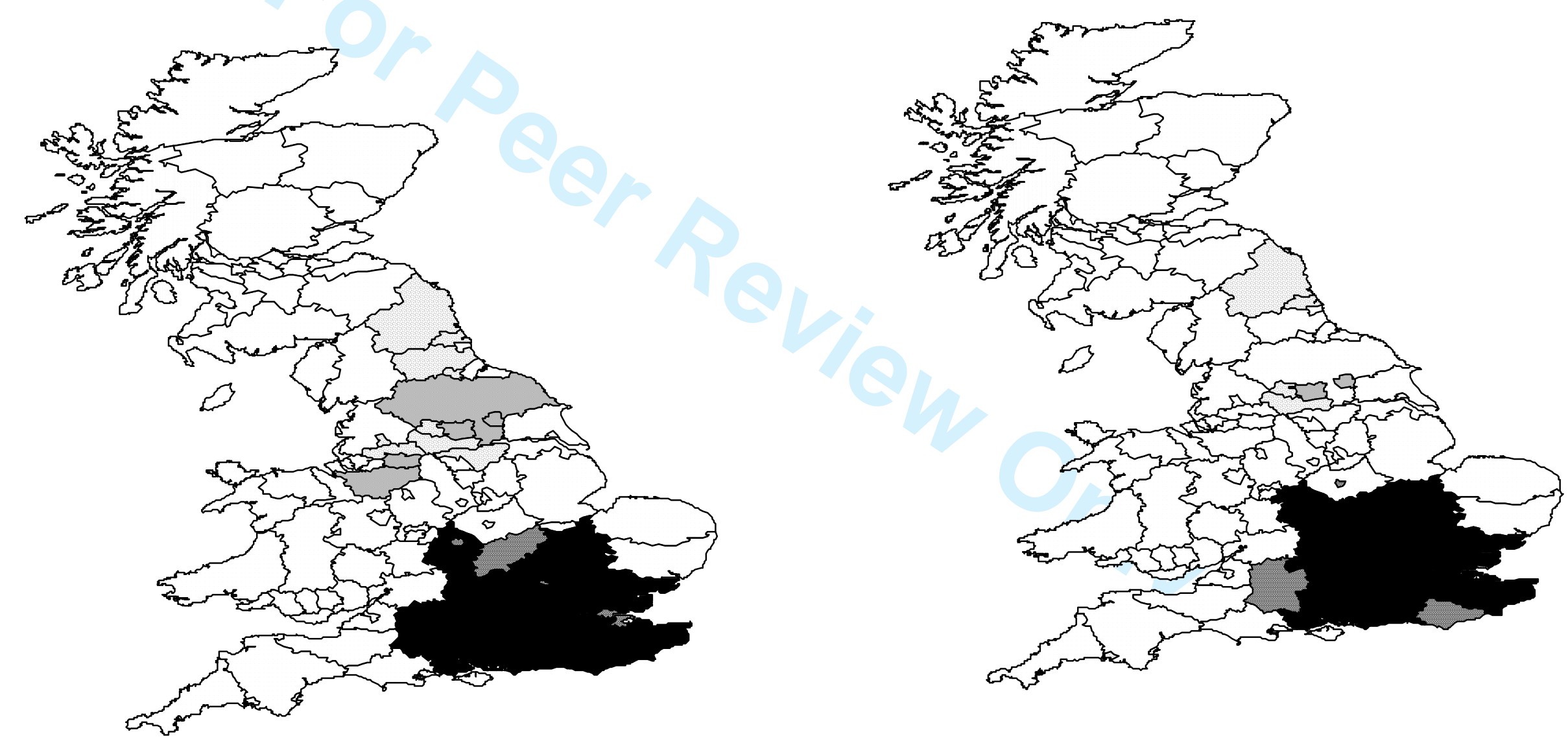